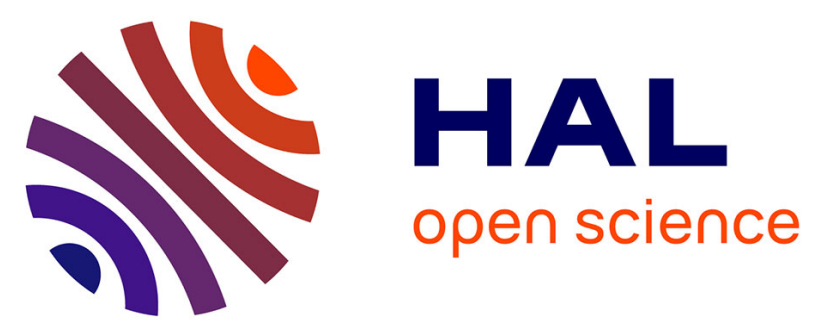

\title{
Overview of SMOS performance in terms of global soil moisture monitoring after six years in operation
} \author{
Yann H. Kerr, A. Al-Yaari, Nemesio Rodriguez-fernandez, Marie Parrens,
} Beatriz Molero, Delphine Leroux, Simone Bircher, Ali Mahmoodi, Arnaud Mialon, Philippe Richaume, et al.

\section{To cite this version:}

Yann H. Kerr, A. Al-Yaari, Nemesio Rodriguez-fernandez, Marie Parrens, Beatriz Molero, et al.. Overview of SMOS performance in terms of global soil moisture monitoring after six years in operation. Remote Sensing of Environment, 2016, 180, pp.40-63. 10.1016/j.rse.2016.02.042 . insu-01321425

\section{HAL Id: insu-01321425 https://hal-insu.archives-ouvertes.fr/insu-01321425}

Submitted on 24 Jan 2022

HAL is a multi-disciplinary open access archive for the deposit and dissemination of scientific research documents, whether they are published or not. The documents may come from teaching and research institutions in France or abroad, or from public or private research centers.
L'archive ouverte pluridisciplinaire HAL, est destinée au dépôt et à la diffusion de documents scientifiques de niveau recherche, publiés ou non, émanant des établissements d'enseignement et de recherche français ou étrangers, des laboratoires publics ou privés. 


\title{
Overview of SMOS performance in terms of global soil moisture monitoring after six years in operation
}

\author{
Y.H. Kerr ${ }^{\text {a,* }}$, A. Al-Yaari ${ }^{\text {b }}$, N. Rodriguez-Fernandez ${ }^{\text {a }}$, M. Parrens ${ }^{\text {a }}$, B. Molero ${ }^{\text {a }}$, D. Leroux ${ }^{c}$, S. Bircher $^{\text {a }}$, \\ A. Mahmoodi ${ }^{\text {a }}$, A. Mialon ${ }^{\text {a }}$, P. Richaume ${ }^{\text {a }}$, S. Delwart ${ }^{\text {d }}$, A. Al Bitar ${ }^{\text {a }}$, T. Pellarin ${ }^{\text {c }}$, R. Bindlish ${ }^{\text {e }}$, T.J. Jackson ${ }^{\text {e, }}$ \\ C. Rüdiger ${ }^{\mathrm{f}}$, P. Waldteufel ${ }^{\mathrm{g}}$, S. Mecklenburg $^{\mathrm{d}}$, J.-P. Wigneron ${ }^{\mathrm{b}}$ \\ a CESBIO (UMR 5126 - CNES, CNRS, UT3, IRD), 18 Avenue Edouard Belin, 31401 Toulouse, Cedex 9, France \\ ${ }^{\mathrm{b}}$ INRA ISPA, Bordeaux, France \\ ' Univ. Grenoble Alpes, CNRS, LTHE, Grenoble, France \\ d ESA ESRIN, Frascati, Italy \\ e USDA ARS, Belstville, MD, USA \\ ${ }^{\mathrm{f}}$ Department of Civil Engineering, Monash University, Clayton, Australia \\ ${ }^{g}$ LATMOS, Paris, France
}

The Soil Moisture and Ocean Salinity satellite (SMOS) was launched in November 2009 and started delivering data in January 2010. The commissioning phase ended in May 2010. Subsequently, the satellite has been in op-eration for over six years while the retrieval algorithms from Level 1 (L1) to Level 2 (L2) underwent significant evolutions as knowledge improved. Moreover, other approaches for retrieval at L2 over land were investigated while Level 3 (L3) and Level 4 (L4) were initiated. In this paper, these improvements were assessed by inter-comparisons of the current L2 (V620) against the previous version (V551) and new products (using neural net-works referred to as SMOS-NN) and L3 (referred to as SMOS-L3). In addition, a global evaluation of different SMOS soil moisture (SM) products (SMOS-L2, SMOS-L3, and SMOS-NN) was performed comparing products with those of model simulations and other satellites. Finally, all products were evaluated against in situ measure-ments of soil moisture (SM). To achieve such a goal a set of metrics to evaluate different satellite products are suggested.

The study demonstrated that the V620 shows a significant improvement (including those at L1 improving L2) with respect to the earlier version V551. Results also show that neural network based approaches can often yield excellent results over areas where other products are poor. Finally, global comparison indicates that SMOS behaves very well when compared to other sensors/approaches and gives consistent results over all sur-faces from very dry (African Sahel, Arizona), to wet (tropical rain forests). RFI (Radio Frequency Interference) is still an issue even though detection has been greatly improved through the significant reduction of RFI sources in several areas of the world. When compared to other satellite products, the analysis shows that SMOS achieves its expected goals and is globally consistent over different eco climate regions from low to high latitudes and throughout the seasons.

\section{Introduction}

A number of studies have shown that knowledge of soil moisture is relevant for many applications and research topics, ranging from climate analysis to weather forecasting as well as from phyto-sanitary issues to water resources management. This is mainly due to the importance of soil moisture in our environment (see for instance (Robinson et al., 2008)). The most obvious role is the need for water by vegetation and living organisms; vegetation uses water available in the root zone

* Corresponding author at: 18 Avenue Edouard Belin, 31401 Toulouse, Cedex 9, France. E-mail address: yann.kerr@cesbio.cnes.fr (Y.H. Kerr). layer while some insects (locusts for instance) have a life cycle driven by the moisture in the first few centimeters of the soil. Also of importance is the role played by the moisture near the surface for soilatmosphere interactions through latent heat exchanges, or as a factor influencing runoff.

As a consequence of these needs many approaches have been explored to provide soil moisture on a global scale with the required frequency and accuracy (Ochsner et al., 2013). From such studies the use of passive microwaves at L-band seems the most promising, even though other approaches including higher frequencies and active systems have shown good potentials (Kerr, 2007). Space borne passive microwaves are limited in spatial resolution, in particular at low frequencies 
(Kerr, 2007). Hence, one of the lingering issues is how to ascertain retrieval quality (i.e. how ground measurements or model outputs can be used to assess the quality of the satellite retrievals), as there are neither exact measurements nor representative sites for all surface conditions and types of the earth (Famiglietti et al., 1999).

The challenge of validating satellite soil moisture retrievals is not new and several attempts have been made by accumulating a large number of single point measurements over large regions. The United States Department of Agriculture (USDA) Soil Climate Analysis Network (SCAN) across the USA (Schaefer, Cosh, \& Jackson, 2007), and databases of the International Soil Moisture Network (ISMN) (Dorigo et al., 2011), initiated by the Soil Moisture and Ocean Salinity (SMOS) project for validating SMOS data, hereafter referred to as sparse networks, are examples in this direction. Another approach aims to establish networks with multiple sensors distributed over regions of 20-40 km, comparable to the resolution of the space borne remote sensing estimates. These types of networks, referred to hereafter as dense networks, were first established in the USA by USDA (Jackson et al., 2010), and then duplicated in several places including HOBE in Denmark (Bircher, Skou, Jensen, Walker, \& Rasmussen, 2012c), OzNet in Australia (Smith et al., 2012), the Upper Danube Basin in Germany (Montzka et al., 2013; dall'Amico et al., 2013; Rotzer et al., 2014), the Valencia Anchor Station (LopezBaeza et al., 2010), and REMEDHUS in Spain (Sanchez, MartinezFernandez, Scaini, \& Perez-Gutierrez, 2012), to name but a few.

The SMOS mission (Kerr et al., 2001; Kerr et al., 2010) is the first mission designed for and dedicated to soil moisture and ocean salinity retrieval. As a consequence, there is an evident need to determine the quality of its geophysical products from L2 (Swath Mode Surface Soil Moisture) (Kerr, Waldteufel, Richaume, Ferrazzoli, \& Wigneron, 2014; Kerr et al., 2012) to L3 (multi-orbit retrievals computed natively from L1 data in an equal area (EASE) grid) and L4 (e.g. surface to root zone estimates). The objective of this activity is not only to estimate the retrieval accuracy, but also to ascertain any limitations in the methodology.

After six years in orbit, SMOS has undergone extensive validation to assess the accuracy of its soil moisture products as a function of biomes and perturbing factors (water bodies, dense vegetation effects, radio frequency interferences), as well as to benchmark it against other satellite soil moisture products. The goal of this paper is to describe the validation approach used and assess the different datasets. The investigation builds on previous studies by expanding the validation, and examines new options and products.

\section{Rationale and caveats}

Validation of soil moisture from space is a challenging task and immediately raises a number of questions, including: 1) what is the depth at which the soil moisture is being observed, 2) how to account for the spatial mismatch between the satellite observations and the ground measurements, 3 ) how to account for perturbing factors, and 4) how to best inter-compare results.

It is not our intention here to analyze either the contributing depth or how to relate point measurements to satellite estimates, as the subject is vast and has been covered already, though probably not exhaustively (Bindlish \& Barros, 2002; Famiglietti et al., 1999; Nicolai-Shaw, Hirschi, Mittelbach, \& Seneviratne, 2015; Rondinelli et al., 2015). Our intention here is to evaluate the SMOS products and benchmark them using metrics described here. However, it seems useful to recall a few basic principles as some a priori misconceptions or wrong assumptions are often made when validating satellite data.

\subsection{Ground measurements}

Ground measurements are very often labeled as "ground truth", which is misleading as they have their inherent errors and are not necessarily always representative of larger areas. Errors are linked to the measurements themselves as with any instrument, but also with their calibration as the manufacturer values are not always adequate, requiring users to establish their own calibration curves (Rüdiger et al., 2010; Bircher et al., 2014a). Moreover, the soil type is not always standard and the response can be significantly different for various types (Bircher et al., 2014b). Also, the volume sampled by the probe is not necessarily for the expected thickness layer (Rondinelli et al., 2015) and the soil air can have an important impact. A typical probe placed at $5 \mathrm{~cm}$ below the surface will for instance give a weighted value corresponding to a volume of soil with a diameter of several $\mathrm{cm}$ depending on both the soil type and the probe type (typically $5 \mathrm{~cm}$ see (Vaz, Jones, Meding, \& Tuller, 2013)). Moreover, some probes are placed vertically and others horizontally. If there is an air-soil interface in the volume, it will also affect the results. Last but not least, the location of the probe is crucial and may not always be optimal. Some are close to automatic weather stations or on field borders which may not correspond to the area of interest. Some are left in one place for a long time where the soil compaction, erosion, or even tunnels made by rodents and earthworms can degrade the quality of the measurements.

To overcome some of the issues described earlier three main approaches have been considered. The first one is to take a large network and filter out the anomalous/malfunctioning sites in order to improve the overall statistical representativeness (Al Bitar et al., 2012; Schaefer et al., 2007). The second approach consists of placing several probes over a unit (hydrological for instance) to analyze their temporal behavior, and then to establish which probe is the most representative (e.g. the one closest to the mean value of all with the smallest standard deviation) or, alternatively, find a weighting of all the probes that gives the most representative value. Typical examples are the USDA watersheds (Jackson et al., 2010). The limitation here is the difficulty in choosing the best metric to use in selecting the most representative sites at a given spatial scale. Finally, another option is to place the probes at places representative of all the soil and land use possibilities for the given area (Bircher, Balling, Skou and Kerr, 2012). This last method is the most complex, and hence requiring more care to implement, but yields the most satisfying results (Bircher, Skou, \& Kerr, 2013).

\subsection{Model outputs}

The major advantage of using model simulations for validation is that they can be readily computed on spatial scales commensurate with satellite measurements. Depending on the required resolution, they can be also available everywhere. The caveats are that the depths of the different layers of the model are not always compatible with the satellite probing depths and that obviously, models have their own sources of error (surface soil moisture is quite often a "nudging" factor compensating for model differences with reality), which is typically the case for land surface models inside a numerical weather prediction system. A good example can be seen in the deserts which are often quite "wet" in some model simulations see example later in text and on figure Fig. 14).

\subsection{Satellite data}

Some of the first issues to address with respect to the use of satellite data for validation are spatial resolution and sampling. Spatial resolution is directly linked to the physical characteristics of the sensor (antenna size and frequency, altitude and view angle) and is usually characterized by the $-3 \mathrm{~dB}$ antenna power pattern width (HPBW, Half Power Beam Width). The area within the HPBW provides - for a Gaussian pattern $-50 \%$ of the total energy received by the sensor in the main beam. Though, this figure may vary depending on antenna design. To give a concrete example, for SMOS, the average- $3 \mathrm{~dB}$ foot print size is $43 \mathrm{~km}$, but it ranges from a sub satellite circular $27 \mathrm{~km}$ footprint to elliptic shapes having a major axis of over $70 \mathrm{~km}$ at $60^{\circ}$ incidence angle. Over land, the maximum size kept in the $\mathrm{L} 2$ and 3 products is for elliptic footprints with an aspect ratio of $<1.5$ and a surface area less than that of 
an equivalent $55 \mathrm{~km}$ disk diameter. However, this corresponds only to the areas contributing around $50 \%$ of the signal in the main beam. To perform retrievals a $123 \times 123 \mathrm{~km}$ square is considered containing all the areas contributing $99.5 \%$ of the signal measured by the radiometer. It is also worth mentioning that due to the elliptic shape of the $-3 \mathrm{~dB}$ foot print two sequential acquisitions of the same target can have ellipses oriented quite differently and thus not covering the same area. Such a feature is however dampened by the fact that a much larger area is integrated through the antenna pattern. Finally, the integration will also introduce a smearing effect as during the sensor's integration time the satellite moves and/or the antenna spins.

In addition, it is important to distinguish the resolution discussed above with sampling and grid spacing. For a total flux radiometer (such as the Advanced Microwave Scanning Radiometer (AMSR) for instance) integrations can be done with a sampling step smaller than the actual resolution of the instrument (either between two scans or from one integration type to the next). After processing, the data can be restituted on a grid with sampling distance (node spacing) smaller than the actual resolution of the instrument (Gevaert, Parinussa, Renzullo, van Dijk, \& de Jeu, 2016). As a consequence, soil moisture estimations for two adjacent points are not independent. For instance, the $-3 \mathrm{~dB}$ resolution of SMOS is $43 \mathrm{~km}$ on average while some products are provided in grids with a spatial resolution of 15 or $25 \mathrm{~km}$. As a consequence, one must be aware that the resolution should not be mistaken for the sampling or grid spacing.

Another common mistake is to take the time of the overpass as the equator crossing time ( $6 \mathrm{am} / 6 \mathrm{pm}$ for current L-band missions). This is obviously not true as the satellite covers $12 \mathrm{~h}$ of local solar time between two equator crossings, and hence the higher the latitude the more drastic the solar time difference with 6 is. So one should use the actual local solar time or the Universal Time (UT) provided with the data. Also note that between the two extremities of the swath, the local solar time may vary up to half an hour at the equator for SMOS or Soil Moisture Active and Passive (SMAP) satellites. Table 1 summarises the characteristics of the different satellites / sensors used in this study to show their differences and commonalities.

\subsection{Retrieval algorithms and validation issues}

The overarching goal is to evaluate satellite soil moisture products, but also to assess their validity range. For this task, one should be aware of the different types of algorithms as they impact the validation approach and the validity range. One may define three general categories of algorithms: i) those which operate on a node-per-node basis (i.e., a law is defined for each grid-node as in the change detection algorithms), ii) global empirical models based on an empirical law obtained over a "training" set, but applied globally, and iii) grid-node global models, based on a radiative transfer approach, which are generic and applied globally.
The node-per-node approach (category (i)) relies on a fit between ground data and satellite estimates over a given period of time for each grid-node to establish an empirical relationship which is then applied to the whole dataset for the corresponding grid-node. This is generally the case for change detection algorithms. Generally, the references used for the fit are model outputs, and ground measurements can be used in addition when available. This method, although straightforward and easy to implement, has a drawback that it is mimicking the model used, and when ground data are also used, it biases the evaluation. The approach will give good results when compared to the model or ground measurements used in the training but, otherwise, cannot be guaranteed to work at other locations. Consequently, it may also give strange results in areas where the training set is non-existent or subject to errors.

Global empirical algorithms (category (ii)) use either an empirical approach, which is applied globally, or per biome type. The empirical law can be based on simple parametric physical laws (Al-Yaari et al., submitted for publication) or purely mathematical parametric models such as neural networks (Rodriguez-Fernandez et al., 2015). Caveats on this approach are linked to the training dataset used to determine the free parameters of the empirical relation (as above). However, when the empirical relation is global and has not been obtained in a point by point basis, it can be more rigorously validated because the training and the validation datasets can be completely distinct (data from sites that will be used for the validation can be completely excluded from the training dataset).

Finally, the radiative transfer model approach (category (iii)) has the advantage of being more robust and more likely to evolve as research progresses, since poor results can lead to model improvements, and the models are generally physically based, rather than empirical. Caveats include that the models are sometimes limited (for instance in the case of wet snow) and/or require sophisticated pieces of information in auxiliary files that are not always available, and thus have to be replaced by "proxies".

\subsection{Suggested metrics and validation approaches}

Given that satellite soil moisture validation is challenging and has a number of unresolved key points, different approaches are suggested below that can be used to assess the quality of the retrieved soil moisture products. Two complementary approaches have been used to attain the required data for the validation of soil moisture products retrieved from satellite observations, and together, they constitute the core of SMOS validation: 1) short-term airborne campaigns with intense ground sampling, and 2) soil moisture networks. Via the airborne measurements with a footprint of a few kilometers, the first method offers the advantage of stepwise validation across spatial scales, as well as direct comparison at brightness temperature level. The second method allows long-term monitoring at high temporal resolution. All of these features are relevant for the assessment of a parameter that is highly

Table 1

Microwave satellite specifications, showing the spatial resolution ( $-3 \mathrm{~dB}$ footprint), sampling, incidence angles and sensitivity of the instruments used in this study.

\begin{tabular}{|c|c|c|c|c|}
\hline Satellite/Sensor/Frequency & $3 \mathrm{~dB}$ foot print & Sampling & Angles & Sensitivity \\
\hline AQUA/AMSR-E/6.925 GHz & $74 \times 43 \mathrm{~km}$ & $10 \mathrm{~km}$ & $55^{\circ}$ & $0.3 \mathrm{~K}$ \\
\hline AQUA/AMSR-E/10.65 GHz & $51 \times 30 \mathrm{~km}$ & $10 \mathrm{~km}$ & $55^{\circ}$ & $0.6 \mathrm{~K}$ \\
\hline AQUA/AMSR-E/18.7 GHz & $27 \times 16 \mathrm{~km}$ & $10 \mathrm{~km}$ & $55^{\circ}$ & $0.6 \mathrm{~K}$ \\
\hline SMOS/SMOS/1.4 GHz & 43 km (average over FOV) & $\begin{array}{l}15 \mathrm{~km} \text { (L2) } \\
25 \mathrm{~km} \text { (SMOS-L3 CATDS) }\end{array}$ & $0^{\circ}-60^{\circ}$ & $\begin{array}{l}3.5 \mathrm{~K} \text { (single snapshot; } 0.5 \mathrm{~K} \\
\text { for a multi-angular pixel) }\end{array}$ \\
\hline SAC-D/Aquarius/1.4 GHz & $\begin{array}{l}94 \times 76 \mathrm{~km} \\
120 \times 84 \mathrm{~km} \\
156 \times 96 \mathrm{~km}\end{array}$ & $1^{\circ}$ & $29.36^{\circ}, 38.49^{\circ}, 46.29^{\circ}$ & $0.09 \mathrm{~K}$ \\
\hline GCOM-W/AMSR2/6.925 GHz & $61 \times 35 \mathrm{~km}$ & $10 \mathrm{~km}$ & $55^{\circ}$ & $0.3 \mathrm{~K}$ \\
\hline GCOM-W/AMSR2/7.3 GHz & $61 \times 35 \mathrm{~km}$ & $10 \mathrm{~km}$ & $55^{\circ}$ & $0.3 \mathrm{~K}$ \\
\hline GCOM-W/AMSR2/10.65 GHz & $41 \times 24 \mathrm{~km}$ & $10 \mathrm{~km}$ & $55^{\circ}$ & $0.6 \mathrm{~K}$ \\
\hline GCOM-W/AMSR2/18.7 GHz & $22 \times 13 \mathrm{~km}$ & $10 \mathrm{~km}$ & $55^{\circ}$ & $0.6 \mathrm{~K}$ \\
\hline SMAP/radiometer/1.4 GHz & $47 \times 51 \mathrm{~km}$ & $36 \times 36 \mathrm{~km}$ & $40^{\circ}$ & $1.3 \mathrm{~K}$ \\
\hline
\end{tabular}


variable in both space and time, and across scales. Basically, the metrics have to be adapted to the types of measurements used as references. However, very often, the accuracy of the reference measurements is not accounted for, neglecting the fact that ground/in situ measurements have their own imperfections.

\subsubsection{Metrics for site based validation (dense networks)}

In the present study, we will consider a set of sites, generally accepted with respect to the quality of the ground measurements and their representativeness, and compare their measurements to the satellite estimates. As much as possible, the selected sites represent the main biomes where soil moisture is retrieved. In order to make sure that various aspects of the signal are evaluated properly, metrics and statistical criteria were obtained in several ways. The first aspect to look at consists of general statistics over time (correlation coefficient (R), bias (B), Root Mean Square Error (RMSE), Standard Deviation (STD)) or standard deviation of the differences between the two series (STDE, Standard Deviation of the Error) or, as it is often called, unbiased RMSE (ubRMSE). The STDE terminology used in this paper, corresponds to a direct estimate, and can be defined as follows:

$S T D E=\operatorname{sqrt}($ variance $($ TimeSeries $1-$ TimeSeries 2$))$.

The statistical criteria as well as triple collocation analysis will be used in this paper. The presentation of the results will be given both in numerical form and Taylor diagrams (Taylor, 2001) or scatter plots. We also consider temporal evolution, as for some applications (hydrology for instance) dry-downs or wet/dry cycles have to be well represented. Finally, it is useful to compare cumulative distribution plots in order to analyze the similarities and differences between ground measurements and satellite observations, especially when the distributions are not linearly related (in the latter case the traditional metrics (B, STDE, R) might be misleading).

\subsubsection{Use of sparse networks}

The sparse in situ networks have the advantage of covering large areas, but at the cost of reduced quality and/or representativeness. Often the data have to be thoroughly quality checked and filtered before use, as it is not always done. Sometimes the temporal coverage is limited and/or includes gaps. Nevertheless, some sites are very useful for the extent and range of biomes/climates they offer. These sparse networks cannot be compared to dense networks without representation issues being addressed. Hence, only statistical criteria over a large number of sparse in situ networks can be considered. The available sparse networks are SCAN, SNOw TELemetry (SNOTEL), Atmospheric Radiation Measurement (ARM), OzNet (see Section 3.2) to name but a few amongst the largest available (see Table 2). Also note that OzNet is both a dense network for some clusters, and a sparse one. Sparse networks have been gathered for ease of use into the ISMN (Dorigo et al., 2011), though with sometimes limited temporal ranges. As many retrieval schemes are trained on these well-known databases (especially algorithms from category (i)), the node-per-node type, to extend as much as possible the validity range), it is useful to find for comparison or validation exercises sites that do not belong to any of these sparse networks or catalogue of networks.

\subsubsection{Model outputs}

In order to assess the quality of soil moisture data at a global scale and to identify areas where retrievals differ in terms of quality/accuracy, it is customary to compare different satellite datasets and/or model outputs together. The idea is not to use the model data as the "truth" since they are as complex as satellite datasets to validate, and may not reflect the true local conditions. However, the limitations of some model data are sufficiently known by users of the numerical weather prediction (NWP) community, and offer a unique tool to compare satellite data against each other at the global scale. A great advantage is that NWP
Table 2

Main characteristics of the Sparse Networks used in this study. The two numbers following the network depth are the upper and lower depths sampled by the sensor in meters. For a sensor installed horizontally the two numbers are the same. Note that the watersheds are included for reference though they are dense networks. Geographical locations are shown on Fig. 1.

\begin{tabular}{lll}
\hline $\begin{array}{l}\text { Network name and sampling depth } \\
(\mathrm{m})\end{array}$ & Number of sites & $\begin{array}{l}\text { Average number of } \\
\text { points }\end{array}$ \\
\hline AMMA-0.05-0.05 & 6 & 94.3 \\
ARM-0.025-0.025 & 18 & 115.1 \\
ARM-0.05-0.05 & 21 & 118.0 \\
DAHRA-0.05-0.05 & 1 & 189.0 \\
OZNET-0.00-0.05 & 13 & 54.4 \\
OZNET-0.00-0.08 & 8 & 69.5 \\
PBO-H2O-0.00-0.05 & 15 & 72.4 \\
SCAN-0.05-0.05 & 128 & 133.5 \\
SNOTEL-0.05-0.05 & 191 & 111.1 \\
USCRN-0.05-0.05 & 72 & 146.4 \\
Watershed LR-0.05-0.05 & 1 & 221.0 \\
Watershed LW-0.05-0.05 & 1 & 234.0 \\
Watershed WG-0.05-0.05 & 1 & 214.0 \\
\hline
\end{tabular}

models are also global datasets, in contrast to in situ measurements. The important point is that model data only allow checking consistency or general features, and not validation, and are only used as such in this paper.

\section{Data Used}

\subsection{Dense networks}

\subsubsection{Watersheds}

Four watersheds located in the United States were selected for this study: Little River (LR) in Georgia, Little Washita (LW) in Oklahoma, Walnut Gulch (WG) in Arizona, and Reynolds Creek (RC) in Idaho. They are all managed by the United States Department of Agriculture (USDA) Agricultural Research Service (ARS) and provide the benefit of a dense instrumental network set on each of the watersheds where surface soil moisture and temperature sensors ( $5 \mathrm{~cm}$ depth) have been acquiring data on an (at least) hourly basis since 2002. Comparisons can be made between the closest in situ measurement in time (average value of the different sensors) and the nearest satellite retrieval to the watershed center. As in (Jackson et al., 2012; Jackson et al., 2010; Leroux et al., 2014), the average in situ value is supposed to represent the size of the SMOS footprint. These four watersheds were also selected for their wide variety of soil types, crop types, and climates. LR is the most humid site with an annual precipitation amount of $1200 \mathrm{~mm}$, mostly covered by row crops and forests. At the other extreme, WG is the driest site with $350 \mathrm{~mm}$ of rain (annual average), and is covered by shrub land used for range activities. With a sub-humid climate, the LW watershed is mostly used for range and agricultural activities with wheat crops and grass covers. Finally, RC is located in a mountainous area and thus represents a challenging site when compared to satellite observations. Its climate is classified as semiarid, but frozen soils are very frequent in winter, adding another difficulty to the comparison. Additional descriptions of the watersheds can be found in (Jackson et al., 2010).

\subsection{2. $\mathrm{HOBE}$}

The study site of the Danish Hydrological OBsErvatory (HOBE, www.hobe.dk) is situated in the Skjern River Catchment. Nearly $80 \%$ of this region is under intensive cultivation, intermixed with patches of spruce forest $(\sim 10 \%)$, as well as heath/grassland $(\sim 6 \%)$, and the majority of soils are very sandy (75\%-100\% sand). SMOS DGG node 2002029 (55.957 N/9.131E) and the surrounding area of the major signal contribution ( $44 \mathrm{~km} \times 44 \mathrm{~km}$ ) was selected for intensive validation campaigns of the SMOS L1C Brightness Temperature (TB), L2 Soil Moisture, as well as auxiliary data products (Bircher, Balling, Skou and Kerr, 2012; Bircher, Merlin, Andreasen, 
Andreasen, Sonnenborg, Jensen, Kerr and IEEE, 2012b; Bircher et al., 2013). This SMOS "grid-node" is representative of the land surface conditions of the catchment and exhibits minimal impact from open water. During fall 2009, a soil moisture and soil temperature network with 30 stations was installed within the grid-node, arranged along the long-term precipitation gradient and with a distribution of the stations made in agreement with the respective fractions of classes representing the prevailing environmental conditions, in order to obtain a representative in situ soil moisture average at SMOS spatial scale (Bircher, Balling, Skou and Kerr, 2012).

\subsubsection{AMMA-CATCH}

Three soil moisture sites, located in Mali, Niger, and Benin in West Africa, were installed in 2005-2006 and belong to the African Monsoon Multidisciplinary Analyses - Couplage de l'Atmosphère Tropicale et du Cycle Hydrologique (AMMA-CATCH) observatory (www.amma-catch. org; Lafore et al., 2010). The Niger and Benin sites are still operational today. The Niger site is a typical Sahelian rain fed cultivated area and is located about $50 \mathrm{~km}$ East of Niamey $\left(13.645^{\circ} \mathrm{N}-2.632^{\circ} \mathrm{E}\right)$. The annual rainfall amount ranges from 300 to $600 \mathrm{~mm}$ from year to year. The Niger site is mainly tiger bush on the plateaus and fallow savannah and pearl millet crop fields on the sandy slopes (Louvet et al., 2015). Five soil moisture stations within a $0.25^{\circ}$ area provide soil moisture measurements representative of different land covers from the near surface (at $5 \mathrm{~cm}$ depth, 6 sensors) to $1.5 \mathrm{~m}$. The Benin site is located $400 \mathrm{~km}$ south of the Niger site, in a Soudanian climate. The observed annual rainfall is about $1200 \mathrm{~mm}$. Most of the ground-based instruments are located in the North-West part of the Ouémé catchment $\left(9.745^{\circ} \mathrm{N}-1.653^{\circ}\right.$ E). Nine surface soil moisture sensors $(0-5 \mathrm{~cm})$ within a $0.25^{\circ}$ area are averaged in order to be representative of the soil moisture at the $0.25^{\circ} \times 0.25^{\circ}$ scale. With more water available, the vegetation is significantly denser than at the Niger site and woody savannah and tropical forest vegetation is typical of this site.

\subsection{Sparse networks}

The SCAN network of the U.S. Department of Agriculture (Schaefer et al., 2007) has been widely used to evaluate modeled soil moisture products as well as soil moisture retrievals from remotely sensed data (ASCAT, SMOS, etc.), including monthly estimates using Neural Networks (NN) retrievals. In this study, the SCAN data were obtained from ISMN. As L-band radiation is emitted by the first few centimeters of the soil, the soil moisture products were compared to in situ soil moisture measurements in the $0-5-\mathrm{cm}$ depth range.

The U.S. Climate Reference Network (USCRN) is a network of climate monitoring stations with sites across the U.S.A., managed and maintained by the National Oceanic and Atmospheric Administration (NOAA). The sensors used in this study are horizontally installed at $5 \mathrm{~cm}$ (Bell et al., 2013).

DAHRA is one station in Senegal (Tagesson, Fensholt, Guiro, et al., 2014). The sensors sampling horizontally the $5 \mathrm{~cm}$ depth were used in this study.

ARM is run by the U.S. Department of Energy as part of the Atmospheric Radiation Measurement Climate Research Facility. Here, the sensors sampling horizontally the $2.5 \mathrm{~cm}$ (ARM-0.025-0.025) and the $5 \mathrm{~cm}$ soil depth (ARM-0.05-0.05) were used.

$\mathrm{PBO}-\mathrm{H} 2 \mathrm{O}$ is a network that was originally developed to evaluate the use of GPS reflection data to measure soil moisture (Larson et al., 2008). It contains 109 stations and the sensors sampling the $0-5 \mathrm{~cm}$ surface soil layer were used.

SNOTEL is a network with a large number of stations (420) operated by the Natural Resources Conservation Service (NRCS) of the USDA (Leavesley et al., 2010). The sensors sampling horizontally the $5 \mathrm{~cm}$ soil depth were used in the current study.

OzNet is a network established in SE Australia in the Murrumbidgee river catchment (Murray-Darling basin) (Smith et al., 2012). Two sets of measurements are available: 18 stations provide SM integrated over the $0-8 \mathrm{~cm}$ soil layer (Campbell Scientific water content reflectometers put in the soil at an angle) - it is actually a "sparse network") and 20 stations over the $0-5 \mathrm{~cm}$ soil layer (Stevens Hydra Probe - "dense network").

Fig. 1 shows the in situ sites used in this study. Networks including a large number of sites are available in the USA (SCAN for instance with over 200 sites) and Australia (40 sites within $60 \mathrm{~km}$ in OzNet). Other available sites cover a large range of climates from arid to tropical humid (see also Table 2 ).

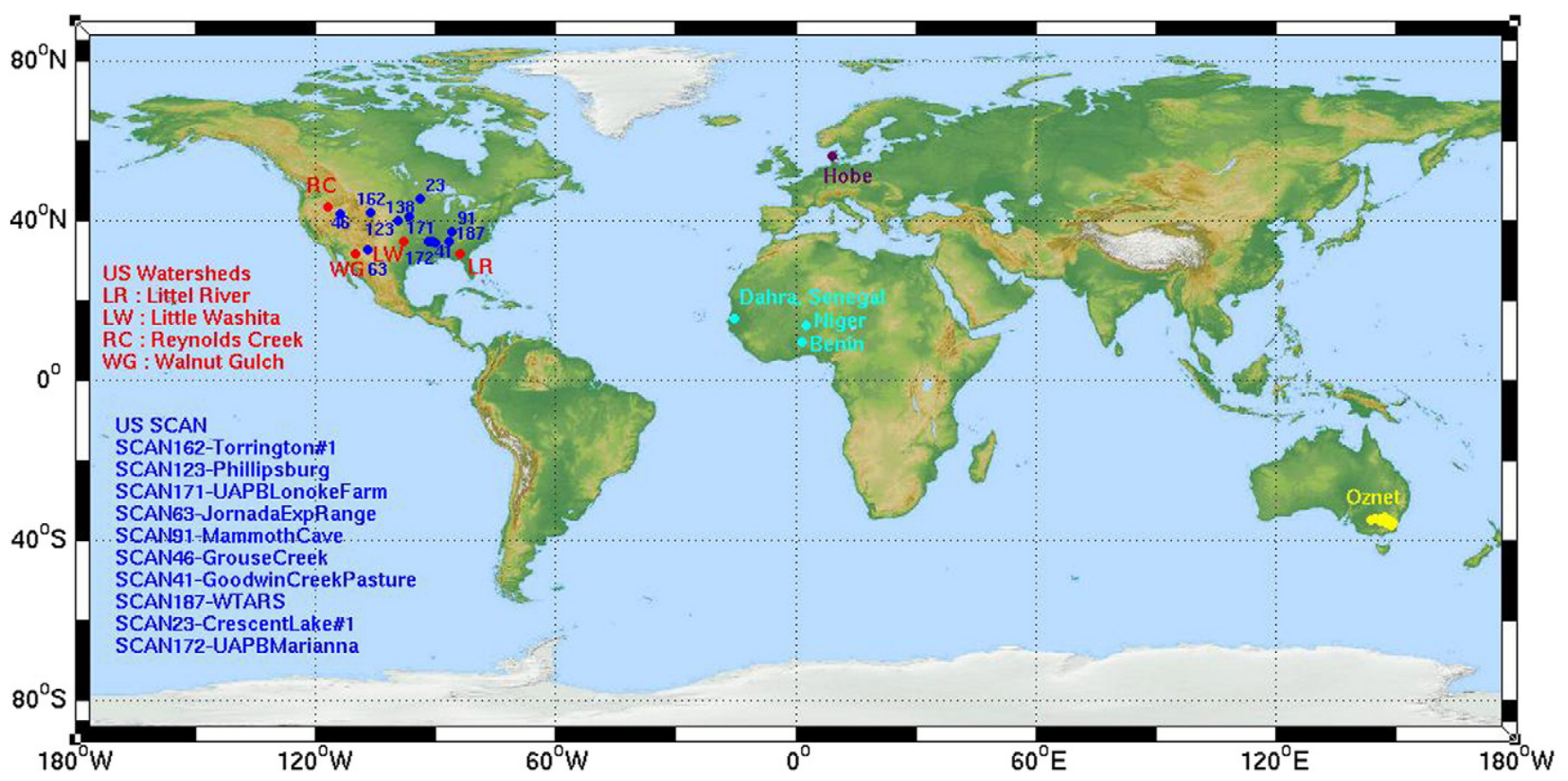

Fig. 1. Spatial distribution of the main in situ validation sites of the SMOS project used in this study. The selected watersheds and SCAN sites are indicated on the left hand side. 


\subsection{Models}

3.3.1. Reanalysis: modern era-retrospective analysis for research and applications (MERRA)

MERRA-Land is an enhanced product from the hydrological fields in the NASA atmospheric reanalysis (Reichle et al., 2011). The enhancements in MERRA-Land include (Reichle et al., 2011): the precipitation forcing was improved by merging MERRA precipitation with a gaugebased data product from the NOAA Climate Prediction Center and the catchment land surface model was updated by using the "Fortuna-2.5" version instead of the "MERRA" version. Reichle et al. (2011) have evaluated these two changes and found that the model's quality was improved in various ways. The MERRA-Land products (Reichle, 2012): (1) can be freely obtained from the Goddard Earth Sciences (GES) Data and Information Services Center (DISC), online on http://disc.sci. gsfc.nasa.gov/mdisc/, (2) cover the 1979-present period and are provided as hourly averages, (3) are described as a simulation product with no assimilation of soil moisture, and (4) are provided with a horizontal resolution of $1 / 2^{\circ}$ latitude by $2 / 3^{\circ}$ longitude and represent a soil layer of $2 \mathrm{~cm}$. Surface soil temperature information was provided with MERRA-Land and was used to filter frozen soil conditions.

\subsubsection{Forecasts: European Centre for Medium-range Weather Forecast (ECMWF)}

Soil moisture data were extracted from the 3-hourly ECMWF forecast system (IFS) SWVL1 parameter (top 0-7 cm soil layer). Since the end of the SMOS commissioning phase (May 2010), eight upgrades of the IFS from cycle $36 \mathrm{r} 2$ to the current cycle $41 \mathrm{r} 1$ were performed. With regard to soil moisture, the cycle $36 r 4$ (2010/11/09) has seen the most significant changes to the soil moisture time series as it is directly affected by the introduction of i) a Simplified Extended Kalman Filter (SEKF) for the global operational soil moisture analysis (Balsamo et al., 2009; de Rosnay et al., 2012), ii) a new snow analysis based on NESDIS snow cover data at 4-km resolution (Dutra et al., 2010), and iii) a monthly varying climatology of leaf area index (LAI) based on MODIS data (Boussetta, Balsamo, Beljaars, Kral, \& Jarlan, 2013). Therefore, in this paper, only data after 9 November 2010 were used to compute quality metrics. The other cycle's upgrades are more related to the atmosphere, ocean or technical changes with less impact on the surface soil moisture forecasts.

The original ECMWF data are provided at the NR400 reduced Gaussian grid $\left(0.225^{\circ}\right.$ at the equator $)$ and were bi-linearly interpolated in space to the SMOS L2 grid (ISEA 4H9) or L3 grid (EASE, $25 \mathrm{~km}$ ), and temporally interpolated to match the time of SMOS overpasses.

\subsection{Satellite data}

\subsubsection{ASCAT}

The Advanced Scatterometer (ASCAT) is an active microwave sensor that was launched in October 2006, following the European RemoteSensing Satellites 1 and 2 (ERS-1 and -2), onboard the Meteorological Operational Platforms METOP-A and METOP-B (since 2012) (Bartalis et al., 2008; Wagner et al., 2013). The METOP-A platform has a sunsynchronous orbit crossing the equator at 09:30 and 21:30 local solar time for descending and ascending orbits, respectively. The ASCAT instrument operates at C-band $(5.3 \mathrm{GHz}$, wavelength $=5.7 \mathrm{~cm})$ in VV (vertical transmitting, vertical receiving) polarization and is a scatterometer system with a low spatial resolution $(25-50 \mathrm{~km})$. Surface soil moisture is retrieved from ASCAT backscatter measurements at the Vienna University of Technology (TU-Wien) using a change detection algorithm. The change detection algorithm was first introduced by (Wagner, Lemoine, \& Rott, 1999) and later improved by (Naeimi, Scipal, Bartalis, Hasenauer, \& Wagner, 2009). The change detection algorithm computes a surface soil moisture index based on scaling the backscatter measurements between the highest (100\% saturation) and the lowest ( $0 \%$ driest) measured values (Wagner et al., 2013) in a unit of degree of saturation. In this study, the ASCAT soil moisture index was multiplied by the soil porosity, using the texture characteristics of the Harmonized World Soil Database (FAO et al., 2009), to convert it to volumetric data $\left(\mathrm{m}^{3} / \mathrm{m}^{3}\right)$ as prescribed by the ASCAT team. Finally, the ASCAT soil moisture products are generated using the soil Water Retrieval Package (WARP) software. In this study, the ASCAT version WARP 5.5 was used.

\subsection{AMSR}

The AMSR instruments are a series of conically scanning passive microwave radiometers, with a direct heritage to Special Sensor Microwave/Imager (SSM/I), and built by the Japan Aerospace Exploration Agency (JAXA). The first two radiometers were operated on ADEOS-2 which only operated for about 10 months due to a solar panel failure, and National Aeronautics and Space Administration (NASA) Aqua's AMSR-E, which was fully operational from May 2002 to October 2011. Currently, a new and improved version of the AMSR-E series (AMSR2) has been flown on board the Global Change Observation Mission 1-Water satellite (GCOM-W1) since May 2012 (Kim, Liu, Johnson, Parinussa, \& Sharma, 2015).

3.4.2.1. AMSR-E. The AMSR-E sensor was launched by NASA in May 2002 onboard the Aqua satellite. Full operations were stopped in October 2011 due to a problem with the rotation of its antenna. The Aqua satellite is in a sun-synchronous orbit, with descending overpass time around 01:30 and ascending overpass time around 13:30 h (local time) at the equator (Demarest, Good, \& Rand, 2001; JAXA, 2006). The AMSR-E sensor observes TB at both horizontal and vertical polarizations, at six frequencies: 6.9 (C-band), 10.65 (X-band), 18.7 (Kuband), 23.8 (K-band), 36.5 (Ka-band), and $89 \mathrm{GHz}$ (W-band), at a single incidence angle of $55^{\circ}$, and with spatial resolutions of $56 \mathrm{~km}$ (6.9 and $10.65 \mathrm{GHz}), 25 \mathrm{~km}(18.7$ and $23.8 \mathrm{GHz}), 15 \mathrm{~km}(36.5 \mathrm{GHz})$, and $5 \mathrm{~km}$ $(89 \mathrm{GHz})$ (JAXA, 2006). For further details on this mission, the reader is referred to the website of NASA: http://www.ghcc.msfc.nasa.gov/ AMSR/index.html.

Since the launch of AMSR-E, several algorithms were developed in order to retrieve soil moisture from its TB observations: (i) the National Snow and Data Centre (NSIDC) algorithm (Njoku, Jackson, Lakshmi, Chan, \& Nghiem, 2003), (ii) the Vrije Universiteit Amsterdam (VUA) algorithm in cooperation with NASA (VUA-NASA) (Owe, de Jeu, \& Walker, 2001); (iii) the Japan Aerospace Exploration Agency (JAXA) algorithm (Koike et al., 2004). The VUA-NASA algorithm evolved into the Land Parameter Retrieval Model (LPRM; Owe, de Jeu, \& Holmes, 2008; Owe et al., 2001)) to retrieve soil moisture from the TB acquisitions from AMSR-E at C- and X-band. The LPRM algorithm simultaneously retrieves both vegetation optical depth and soil moisture using an iterative optimization technique. In LPRM, surface temperature is computed from the Ka-band frequency and the vegetation optical depth is retrieved using the Microwave Polarization Difference Index (MPDI) (Chung et al., 2013). The soil moisture product used in this paper is the LPRM dataset for descending overpasses using only C-band brightness temperatures, for which the data are considered to be more stable (Owe et al., 2008).

3.4.2.2. AMSR2. On May 18th 2012, JAXA launched the AMSR2 onboard the GCOM-W1 satellite (Imaoka et al., 2010; Kim et al., 2015) providing complete coverage of the Earth in 2 days. AMSR2 follows on the heritage of the NASA AMSR-E mission and continues observing TB in both vertical and horizontal polarizations. Several enhancements were introduced to AMSR2 (Imaoka et al., 2010; Kim et al., 2015) such as an improved thermal design for the high temperature noise source, a better spatial resolution due to a larger main reflector with a 2 m diameter, and a new dual polarization channel at $7.3 \mathrm{GHz}$, to mitigate RFI.

Soil moisture is retrieved from the AMSR2 X-band $(10.6 \mathrm{GHz}) \mathrm{TB}$ using a radiative transfer model (Mo, Choudhury, Schmugge, Wang, \& Jackson, 1982) and implementing the JAXA algorithm (Fujii, Koike, \& Imaoka, 2009). Polarization index (PI) and index of soil wetness are 
computed to retrieve soil moisture and vegetation water content simultaneously using a lookup table technique as inverse analysis tables.

AMSR2 started providing soil moisture on July 3, 2012, which can be obtained online from the JAXA Earth Observation Research Center (EORC) on https://gcom-w1.jaxa.jp/. AMSR2 provides soil moisture in both swath (L2) and gridded datasets (L3) at $10 \mathrm{~km}$ and $25 \mathrm{~km}$ resolution. The AMSR2 L3 soil moisture product is provided with a unit of $\mathrm{m}^{3} / \mathrm{m}^{3}$ (volumetric water content) for daily and monthly temporal scales for both the ascending (13:30 local time) and descending (01:30 local time) orbits. In this study, the daily soil moisture products (descending overpass) with a grid sampling of $25 \mathrm{~km}$ were used. A full overview of the similarities/differences between the JAXA and LPRM algorithms can be found in (Kim et al., 2015).

\subsection{SMOS}

The SMOS mission is an European Space Agency (ESA) led mission with contributions from CNES (Centre National d'Etudes Spatiales, France) and CDTI (Centro Para el Desarrollo Tecnológico Industrial, Spain). The primary goals of this Earth Explorer mission are to measure globally and frequently the surface soil moisture over land and sea surface salinity over the oceans (Kerr et al., 2001). The mission relies on a novel instrument design, a two dimensional interferometric instrument operating at L-band $(21 \mathrm{~cm}, 1.4 \mathrm{GHz})$. As a true Earth Explorer, the mission relies on an instrument never used in space for such purposes, to directly measure directly three variables for the first time (ocean salinity (OS) and SM/vegetation optical depth) with a high accuracy. These challenges were met soon after launch with the production of the first global OS and SM fields as well as new products (Mecklenburg et al., 2016-in this issue). Over land, the first challenge was to obtain surface soil moisture fields that fulfilled the requirements (e.g., $0.04 \mathrm{~m} 3 / \mathrm{m} 3$ over non forested areas of medium to low topography without snow of frozen soils at least twice (am and pm) in $<3$ days). Thanks to progress made in image reconstruction techniques, the operational retrieval algorithm (Kerr et al., 2012) was also improved, as described below. Moreover, new retrieval techniques such as simplified approaches or neural networks were tested with very satisfactory results as is described below.

3.4.3.1. Level 2 soil moisture. The $\mathrm{L} 2$ soil moisture algorithm is based on the L-band Microwave Emission of the Biosphere (L-MEB) radiative transfer model (Wigneron et al., 2007). The approach is to retrieve surface characteristics by minimizing the difference between radiative transfer estimates of the TB and actual satellite measurements. The approach relies heavily on the multi-angular measurements available to compensate for the relatively poor radiometric sensitivity of the sensor and to separate the vegetation contribution from the surface contribution. The approach is described in the SMOS Algorithm Theoretical Basis Document (ATBD) (Kerr et al., 2014). Since the general characteristics of the retrieval scheme have been described in (Kerr et al., 2012), we will only expand on the changes associated toV620, which is the current version processed by ESA in the operational center. These modifications are included in the latest version of the ATBD (available from CESBIO www.cesbio.ups-tlse. fr/SMOS_blog/ and ARRAY www.array.ca/smos).

Above all, version 620 differs from the previous V551 by the large improvements in the $\mathrm{L} 1$ which include correction of a mistake in the cross-polarization computations, better calibration (Martin-neira et al., 2016-in this issue), and improved RFI detection (Oliva et al., 2016-in this issue) among other things.

For the L2 product, one may note that the current files (the files containing the retrievals results from previous orbits for vegetation opacity, surface roughness and RFI to constrain the current orbit retrievals) are now (i) built separately for the ascending and descending orbits and (ii) with an enhanced data quality control. Only the retrieved opacity and roughness which are obtained from TB profiles having at least $20^{\circ}$ of incidence angles range and improved chi square (goodness of fit) are retained to update the current files content. These changes allow for the diurnal variations of vegetation water content which may occur between $\sim 6$ am and $\sim 6 \mathrm{pm}$. This led to slightly increasing the validity period of these current files. The forest modeling has also undergone significant improvements and now provides more realistic values of forest opacity and in many cases enables retrieval of soil moisture below forest canopies (Vittucci et al., 2016-in this issue). Other technical aspects involving RFI screening, improvement of the existing retrieval post-uncertainty (DQX which carries over the uncertainties from the observation system to the parameter space through the inverse of the linear tangent model (Jacobian) at the retrieved solution; see (Tarantola, 2004)), model regularization around SM $=0$ (Mialon et al., 2015) are part of this new version 620 . Finally some auxiliary data files were updated. The soil texture map is now at $4 \mathrm{~km}$ resolution and common with the SMAP mission and Globecover V2.3 (V2.2 before) is now used as the land-cover map with an improved quality of the water body fraction estimation. All those changes are described in detail in (Kerr et al., 2014).

3.4.3.2. CATDS Level 3 soil moisture. The SMOS L3 dataset is delivered by the Centre Aval de Traitements des Données SMOS (CATDS) (Jacquette et al., 2010). It includes both a TB dataset (SMOS-L3 TB) where the polarized TB data are expressed in the Earth surface reference frame (vertical, $\mathrm{V}$, and horizontal, $\mathrm{H}$, components) and a retrieved soil moisture dataset (SMOS-L3). The latter is based on the L2 soil moisture retrieval with slight modifications, see (Kerr et al., 2013), that include the use of three overpasses and a time correlation of the vegetation (Al Bitar et al., submitted for publication). The SMOS-L3 data are available in the NetCDF (Network Common Data Form) format, on the EASE Grid (Equal-Area Scalable Earth Grid) version 2 (Brodzik, Billingsley, Haran, Raup, \& Savoie, 2012) which is an equal area grid, with a sampling resolution of $25 \mathrm{~km}$ (at a latitude of $30^{\circ}$ ).

The dataset used in this study (version 300) is issued from the third reprocessing campaign. It is based on ESA L1b (version 6) data and version 620 of the L2 soil moisture processor.

3.4.3.3. Neural network retrievals. The neural network approach is based on a feed-forward neural network using SMOS TB grouped with other sources of information using an approach similar to that of (Rodriguez-Fernandez et al., 2015), i.e., using SMOS-L3 TB as inputs, which are averaged in $5^{\circ}$-width incidence angle bins. It was found that it is possible to define two local normalized indexes $I_{1}$ and $I_{2}$ that improve the neural network results. The first one, $I_{1}$, is a normalization of the TB time series for each spatial grid node defined as:

$I 1(\mathbf{t}, i, j)=\frac{T_{b}(\mathbf{t}, i, j)-T_{b}^{\min }(i, j)}{T_{b}^{\max }(i, j)-T_{b}^{\min }(i, j)}$.

where $\mathrm{t}$ is time, $i, j$, and $T_{b}^{\min }$ and $T_{b}^{\max }$ the minimum and maximum, respectively, of the TB data in the June 2010-June 2013 time series for the grid point $i j$. This index is computed independently for each incidence angle bin and polarization. In addition, taking into account the SM values associated to the maximum and minimum of the local TB time series, one can also define a second index, $I_{2}$, as follows:

$$
\begin{aligned}
& S M^{T_{b}^{\min }}(i, j)+ \\
I 2(\mathbf{t}, i, j)= & +\left[\operatorname{SM}_{b}^{T_{\text {max }}}(i, j)-S M^{T_{b}^{\min }}(i, j)\right] \times \\
& \times I_{1}(\mathbf{t}, i, j)
\end{aligned}
$$

where $S M^{T b}(i, j)$ is the soil moisture corresponding to the TB brightness temperature for grid node $(i, j)$ as determined from the reference SM dataset used to train the neural networks (SMOS L3 SM in the present study, see below). $S M^{T b m i n}(i, j)$ and $S M^{T b m a x}(i, j)$ are the minimum and maximum, respectively, of the $S M^{T b}(i, j)$ data in the time series for the 
grid point $i j$. The correlation of the neural network output with respect to the reference soil moisture dataset increases significantly $(\sim 13 \%)$ when using the index $I_{2}$ (for a given incidence angle range). In addition, when using this index it is possible to use a narrower incidence angle range for the TB data without a significant loss of performances (Rodriguez-Fernandez et al., 2015), and, therefore, increase the swath-width of the neural network retrieval (the swath width is maximum when using only the $40^{\circ}-45^{\circ}$ angle range). Finally, it should be noted that once trained, the neural networks are very fast to apply and, therefore, they are the basis of an algorithm to retrieve soil moisture from SMOS observations in near-real-time (see (Mecklenburg et al., 2016-in this issue).

The NN used in this paper has the same configuration as that of the scheduled NRT SMOS SM product. The input vector is composed of TB data and the corresponding $\mathrm{I} 2$ indexes in three incidence angle bins from 30 to $45^{\circ}$ (both for $\mathrm{H}$ and $\mathrm{V}$ polarizations). Using this incidence angle range allows the retrieval of soil moisture over a swath width of $914 \mathrm{~km}$, which is slightly less than that of the SMOS-L2 or SMOS-L3 products, reducing slightly the temporal coverage. In addition, soil temperature estimates from ECMWF models are also used as inputs to improve the performances of the retrieval. The NN has five non-linear (hyperbolic tangents) neurons in the hidden layer and a second layer with a single linear neuron. In contrast to Rodriguez-Fernandez et al. (2015), who used ECMWF IFS model simulations as reference data to train the NN, here the NN were trained using the SMOS-L3 SM product as reference data. The training database was computed using one day every ten days from June 1st, 2010 to June 23rd, 2013. In addition, only one grid point over three (both in latitude and longitude) was kept for the training database. Data from frozen or snow-covered soil were filtered out from the training database using ECMWF IFS model simulations. Grid nodes close to the location of the in situ sensors used to evaluate the performance of the NN were removed from the training database. Finally, grid points with a probability higher than $20 \%$ of being affected by RFI in the SMOS frequency band were as well removed from the training database using the RFI_Prob parameter of the SMOS-L3 products. The final training database contains $\sim 2.210^{5}$ data samples. The training was done using the gradient backpropagation method and the Levenberg-Marquardt minimization
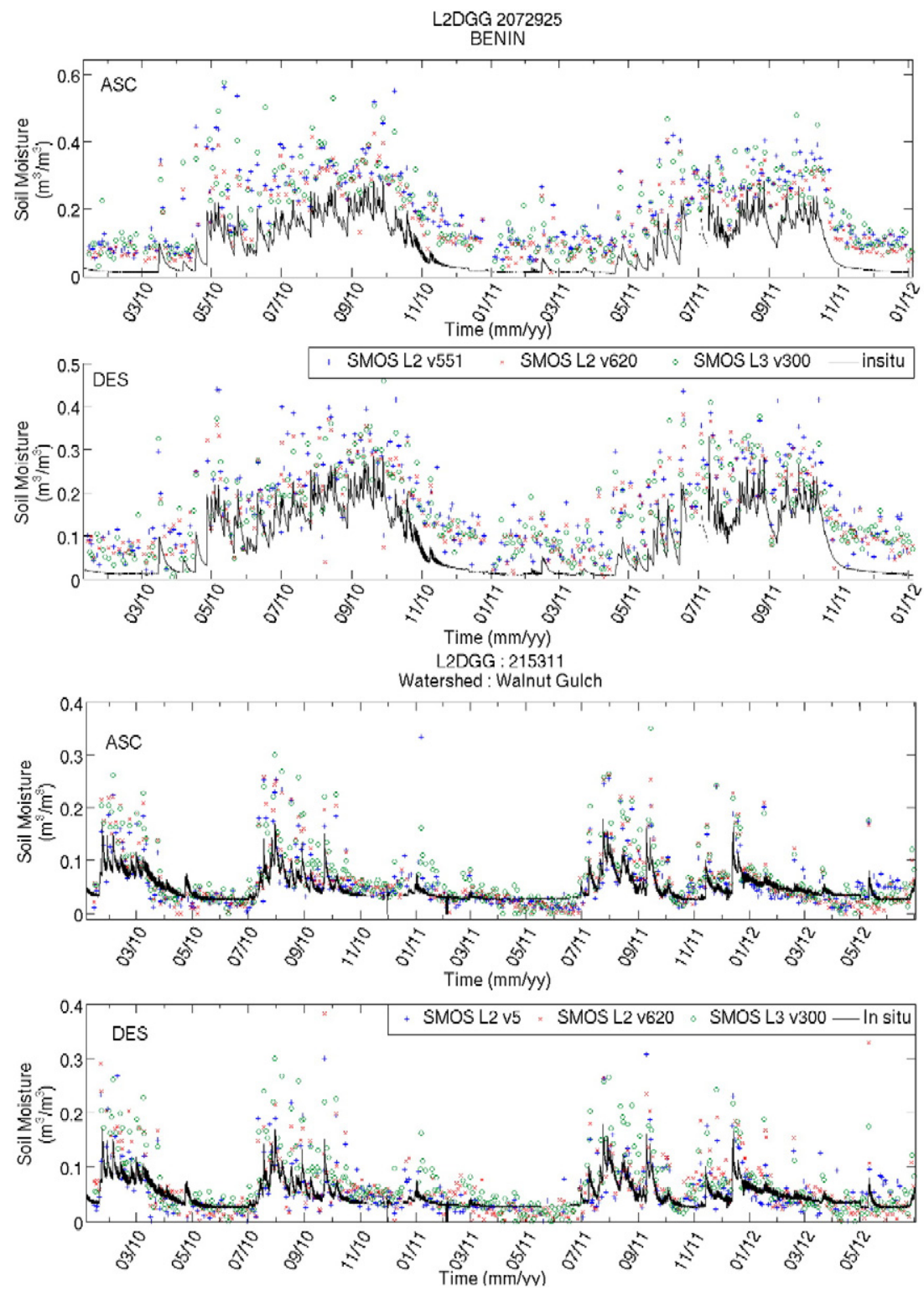

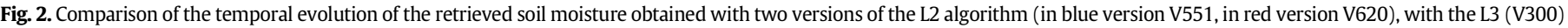

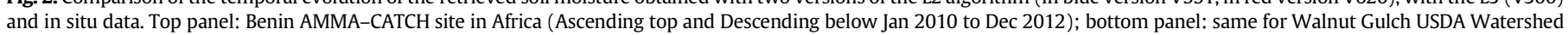
(Ascending and Descending Jan 2011-Dec. 2012). 
WalnutGulch - Ascending orbits

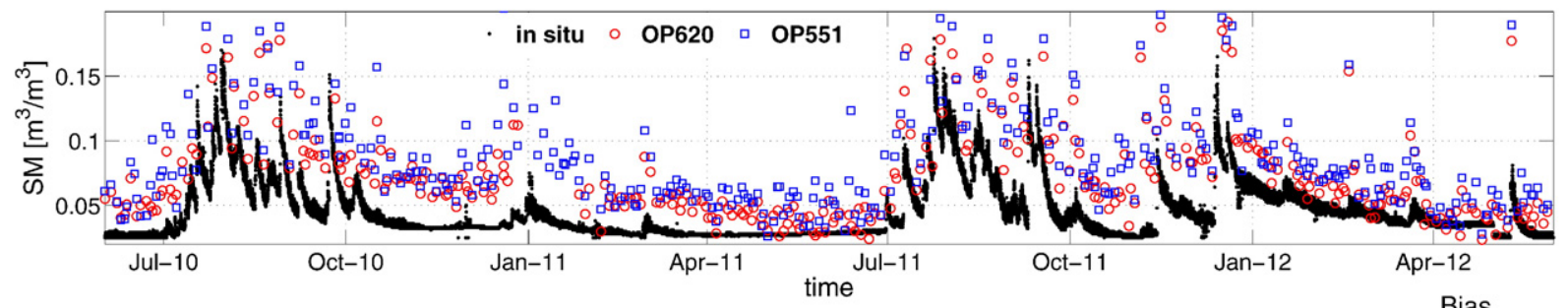

$\Delta$ statistics: Insitu - SMOS

\begin{tabular}{|l|c|c|c|c|c|}
\hline Series & $\mathbf{R}$ & Bias & STDE & RMSE & \#kept \\
\hline \hline OP620 & 0.83 & -0.042 & 0.038 & 0.056 & 360 \\
\hline OP551 & 0.76 & -0.055 & 0.044 & 0.070 & 374 \\
\hline
\end{tabular}

Insitu/SMOS series statistics

\begin{tabular}{|l|c|c|c|c|}
\hline Series & Mean $_{\text {SMOS }}$ & Mean $_{\text {Insitu }}$ & STD $_{\text {SMOS }}$ & STD $_{\text {Insitu }}$ \\
\hline OP620 & 0.043 & 0.084 & 0.021 & 0.054 \\
\hline OP551 & 0.043 & 0.097 & 0.021 & 0.057 \\
\hline
\end{tabular}

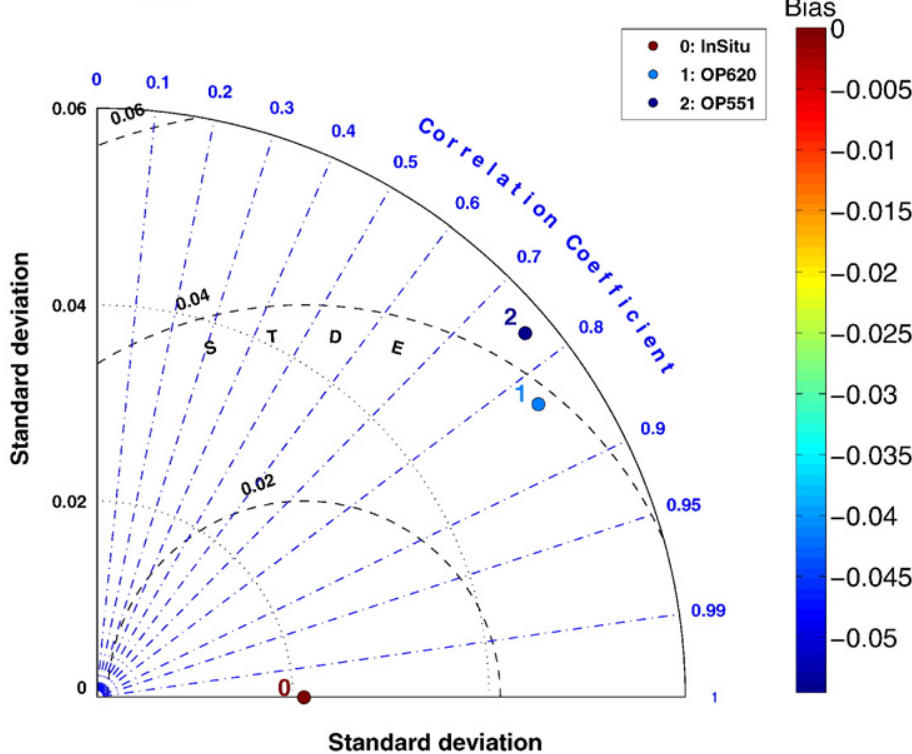

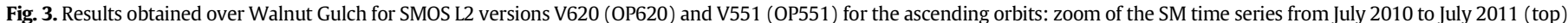

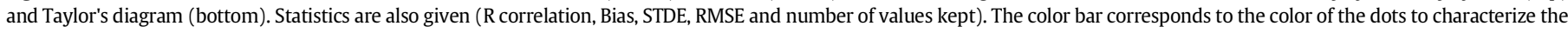
biases.

Table 3

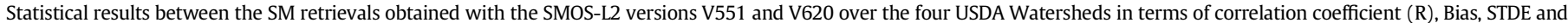
RMSE.

\begin{tabular}{|c|c|c|c|c|}
\hline Site & R (551/620) & Bias $(551 / 620)$ & STDE $(551 / 620)$ & RMSE (551/620) \\
\hline Little River ASC & $0.47 / 0.57$ & $-0.130 /-0.091$ & $0.057 / 0.053$ & $0.142 / 0.105$ \\
\hline Little River DSC & $0.45 / 0.58$ & $-0.110 /-0.070$ & $0.050 / 0.043$ & $0.121 / 0.082$ \\
\hline Little Washita ASC & $0.81 / 0.90$ & $-0.040 /-0.008$ & $0.042 / 0.035$ & $0.058 / 0.036$ \\
\hline Little Washita DSC & $0.83 / 0.85$ & $-0.038 /-0.004$ & $0.042 / 0.037$ & $0.056 / 0.037$ \\
\hline Reynolds Creek ASC & $0.58 / 0.60$ & $0.025 / 0.061$ & $0.072 / 0.070$ & $0.076 / 0.092$ \\
\hline Reynolds Creek DSC & $0.50 / 0.63$ & $-0.007 / 0.023$ & $0.079 / 0.066$ & $0.078 / 0.069$ \\
\hline Walnut Gulch ASC & $0.79 / 0.86$ & $-0.055 /-0.023$ & $0.048 / 0.041$ & $0.073 / 0.047$ \\
\hline Walnut Gulch DSC & $0.77 / 0.73$ & $-0.046 /-0.024$ & $0.040 / 0.038$ & $0.061 / 0.045$ \\
\hline
\end{tabular}

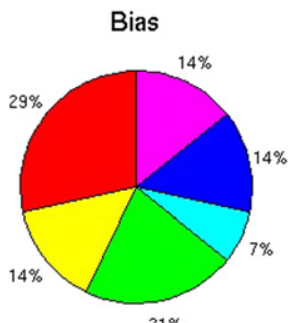

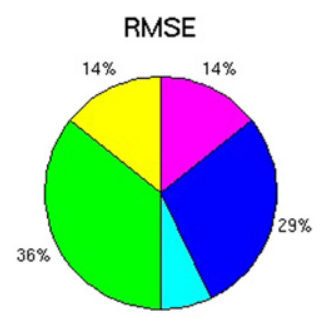
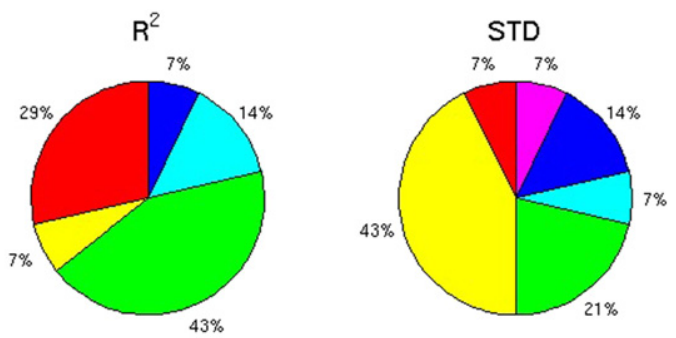

SMOS L3 $\square$ ECMWF $\square$ SMOS-NN $\square$ ASCAT $\square$ SMOS L2

Fig. 4. Percentage of cases where a given dataset ranks best (morning orbits). See Appendix A for details. 
algorithm. A subset containing $60 \%$ of the samples in the training database were used for the training, and $20 \%$ of the samples were used to check the NN performances during the training to avoid over-training. The other $20 \%$ of the samples were used to compare the SMOS-NN output to the reference SM after training. No signs of over-training were observed as the supervised learning was done with a large number of statistically significant samples. As discussed by Rodriguez-Fernandez et al. (2015), the NN is a global method that allows us to check a posteriori the statistical consistency of the reference SM dataset and to correct wrong estimates in that dataset.

\subsubsection{Others (SMAP and Aquarius)}

Aquarius/SAC-D and SMAP are two other L-band radiometers launched by Argentina and by NASA. They are both characterized by the addition of an active system. Aquarius was launched in June 2011 and was operational until June 2015. Its main goal was to retrieve sea surface salinity over ocean, hence the relatively poor spatial and temporal resolutions so as to optimize sensitivity (Le Vine et al., 2014). Over land a soil moisture algorithm was developed and provided good results (Bindlish \& Barros, 2002). SMAP was launched in January 2015, and is dedicated to soil moisture and freeze thaw state monitoring, with very similar coverage characteristics as SMOS for the passive component (Entekhabi et al., 2010; Entekhabi, Yueh, ONeill, et al., 2014) with a slightly better swath and improved sensitivity but only one view angle $\left(40^{\circ}\right)$. These two missions are mentioned here for the sake of completeness but were not used in this study.

\subsection{Data selection rationale}

The remotely sensed soil moisture products are often associated with quality flags that allow quality control prior to the evaluation. For SMOS, grid-nodes with a DQX $>0.06 \mathrm{~m}^{3} / \mathrm{m}^{3}$, or with a DQX equal to fill value (meaning the retrieval failed), or with a percentage of RFI $>10 \%$ were rejected. For ASCAT, grid-nodes with a noise error $(E R R)>14 \%$, frozen temporary, melting water on the surface, and permanent ice were rejected. Furthermore, all the datasets were re-projected from their original coordinate systems onto the EASE V2 $25 \times 25 \mathrm{~km}$ grid, the grid used by SMOS-L3 products, using a nearest neighbor approach (Rüdiger et al., 2009). Finally, MERRA-Land soil moisture gridnodes with soil temperature (from MERRA-Land) $<274 \mathrm{~K}$ were screened out to avoid any frozen soil conditions.

In order to compare different products a common study period is required, if possible. The approach taken depends upon the objectives and is thus described in Section 4.

\section{Results and discussion}

Results are presented in three main groups: 1) improvements of SMOS-L2 version V620 with respect to V551, 2) comparison between several SMOS retrieval algorithms (L2, L3 and Neural networks), and 3) comparison between SMOS and other satellite/model outputs.

\subsection{Comparisons at local scale}

\subsubsection{Dense networks and sites}

In order to keep the presentation focused, we concentrated our analysis on a limited amount of sites for the figures including time series, while using a larger dataset for the statistical analysis. Fig. 2 shows plots of the SM time series for one site in Benin, Africa (AMMACATCH), characterized by a tropical humid climate and a dense vegetation cover, and for one site in the USA (USDA Walnut Gulch watershed) which is arid.

These two examples show that the general behavior of the SM time series is mostly the same between the two algorithm versions with the exception that V620 is a bit drier than V551 for both sites which improves the results. This is shown for the Walnut Gulch site in Fig. 3 which presents a Taylor's diagram and a zoom of the SM time series for one year (July 2010-July 2011) for clarity. The zoom enables us to see that the SM retrievals are drier and closer to the in situ
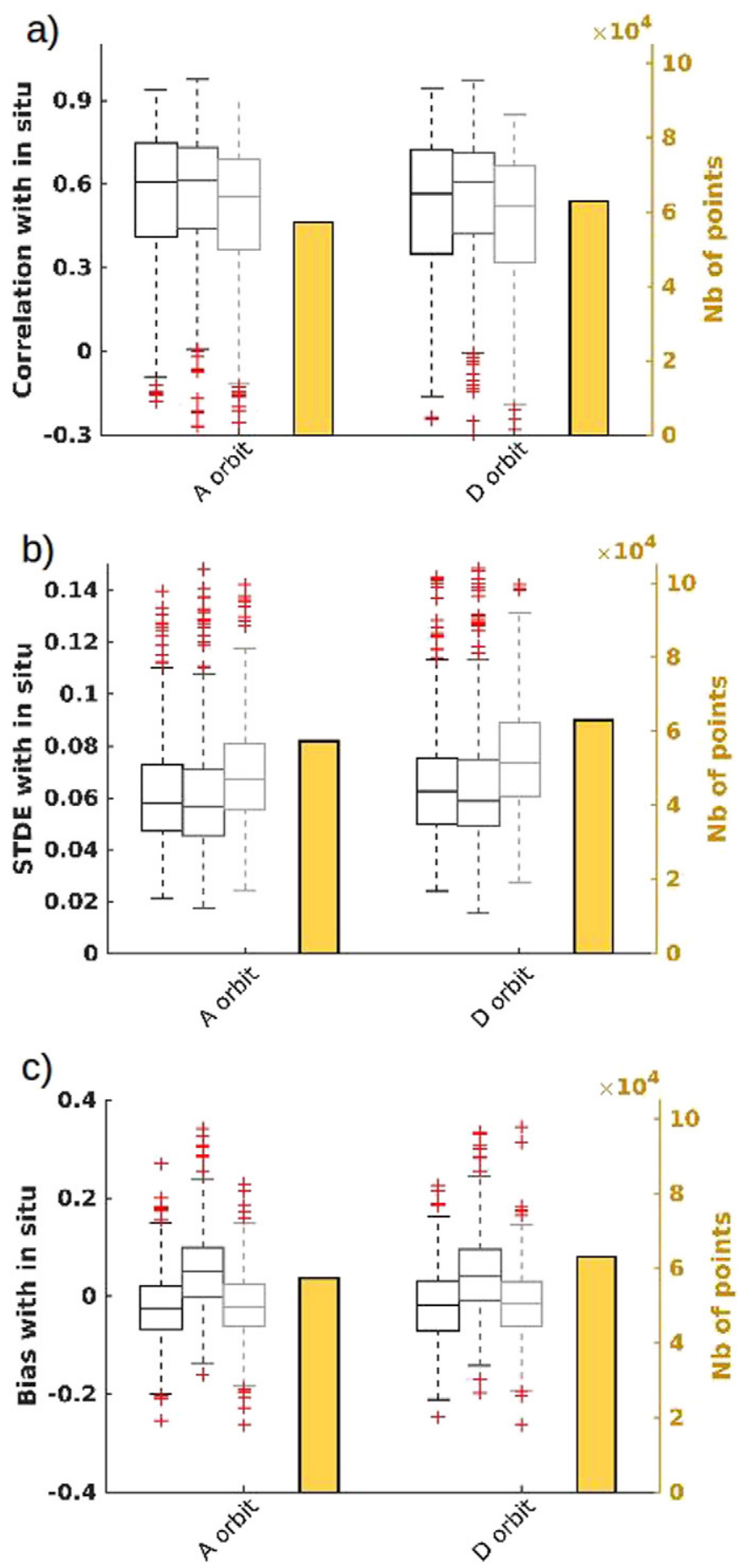

Fig. 5. Evaluation of SMOS NN (black boxes), ECMWF IFS (dark gray boxes) and SMOS L3 (light gray boxes) with respect to in situ measurements. The results were computed site per site. The box plot shows the median value, and 25 th and 75 th percentiles. Points are drawn as outliers (red crosses) if they are larger than $\mathrm{q}_{3}+1.5\left(\mathrm{q}_{3}-\mathrm{q}_{1}\right)$ or smaller than $\mathrm{q}_{1}-$ $1.5\left(q_{3}-q_{1}\right)$, where $q_{1}$ and $q_{3}$ are the values corresponding to the 25 th and 75 th percentiles. The dashed lines extend to the most extreme data value that is not an outlier. Panel (a) shows the correlations with respect to in situ measurements for both ascending and descending overpasses. Panel (b) shows the standard deviation of the difference of the three products with respect to the in situ measurements. Panel (c) shows the bias. The yellow bars show the total number of points in each class (however, as already mentioned the metrics were computed site per site). 
measurements for V620 in comparison to V551. These are only two examples; however, the overall statistics, as presented in the following), also show a clear improvement between versions V551 and V620.

The improvements are shown in Table 3 which summarizes statistical results for the four USDA watersheds. In almost all of the cases the results are better with V620. One may also note that even for the most "difficult" site of Reynolds Creek (located in a mountainous area with frequent occurrence of snow and freezing events) the results are rather satisfactory. One site (Little River) gives poor results for both versions. This was recently explained (Mahmoodi et al., 2015) by wrong estimates of the land use in that area in the ECOCLIMAP database (Masson, Champeau, Chauvin, Meriguet, \& Lacaze, 2003). When using the International Geosphere Biosphere Program (IGBP) classification (Broxton, Zeng, Sulla-Menashe, \& Troch, 2014), results are significantly improved.

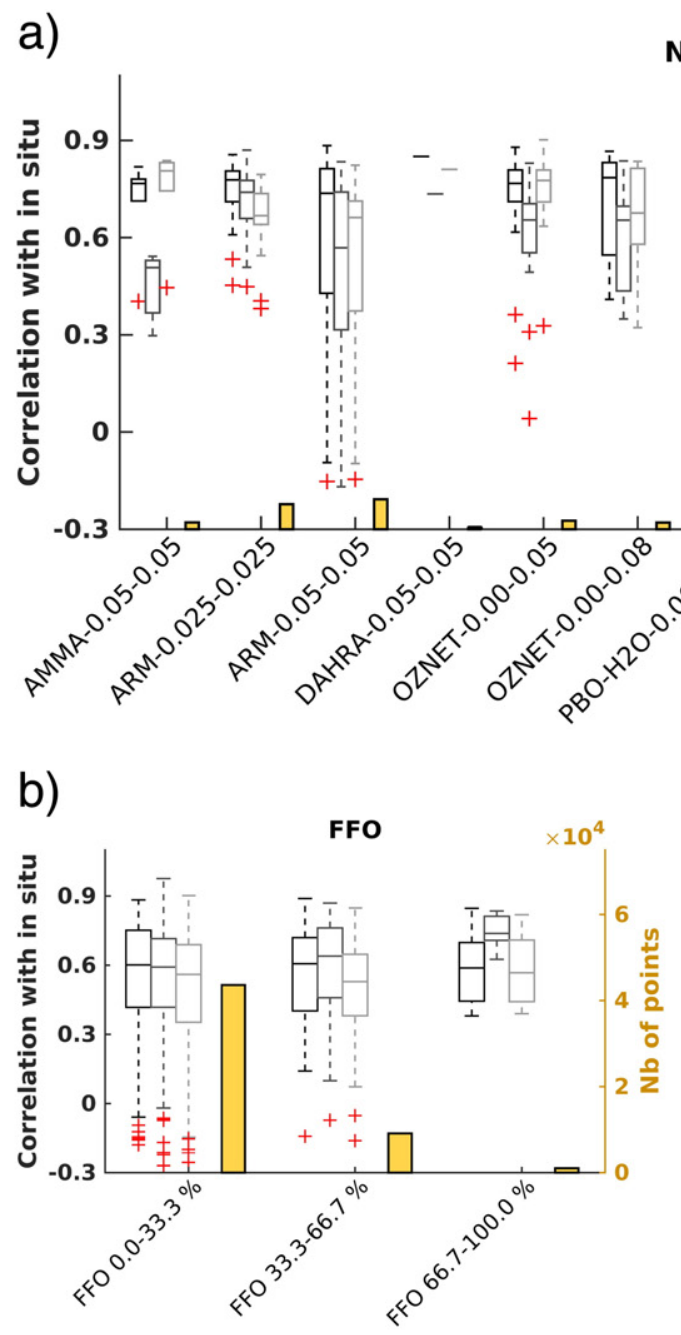

Network

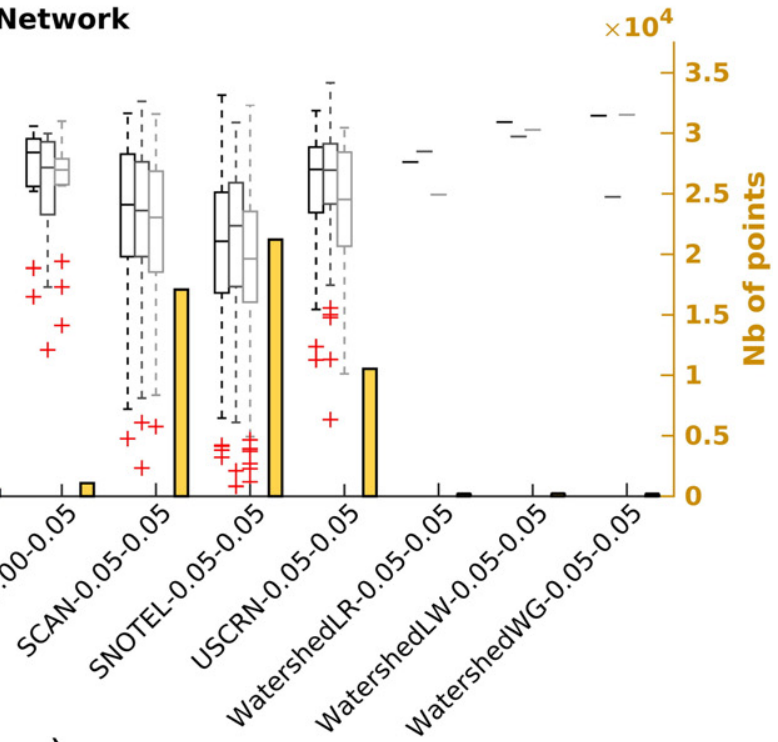

c)

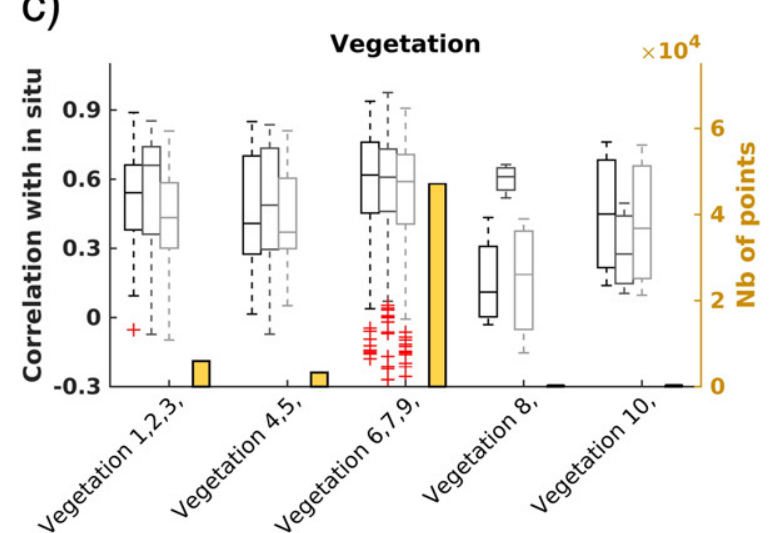

d)

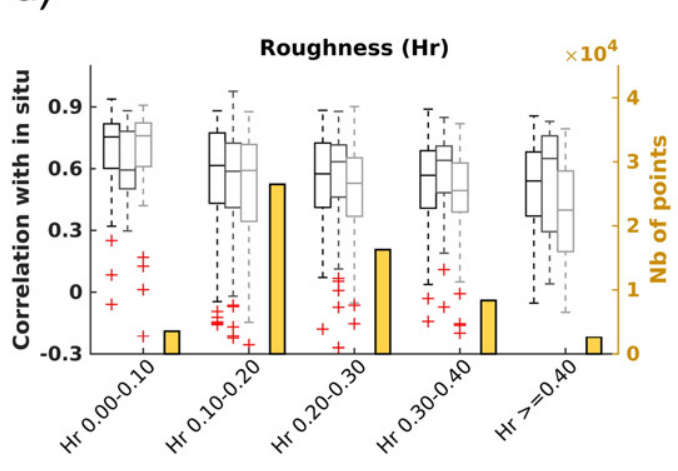

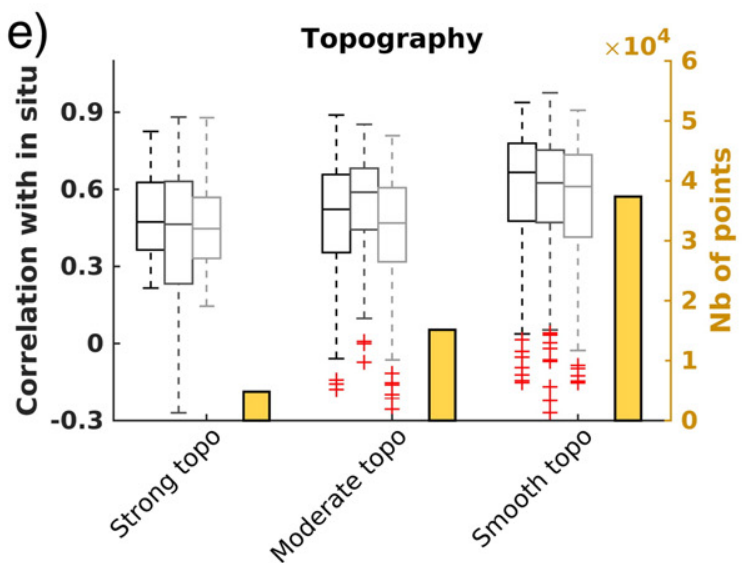

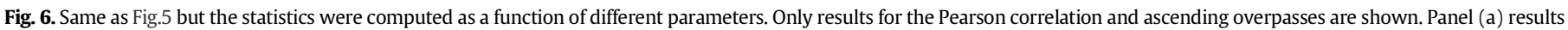

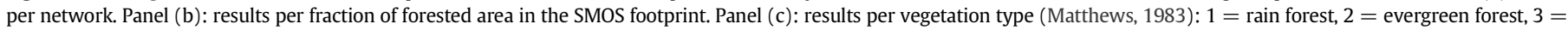

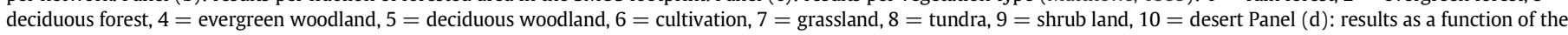
roughness parameter $\mathrm{Hr}$. Panel (e): results are a function of the topography. 
4.1.2. Sparse and dense networks: detailed analysis for some sites

Once the improvement of V620 vs. V551 was ascertained, it was deemed useful to evaluate the different SMOS products (L2 from ESA, L3 from CATDS, neural networks) against NWP simulations and other satellite products over several sites. For this evaluation, 11 SCAN sites were identified by (Al Bitar et al., 2012) as being of good quality and representative of an AMSR-E/ASCAT/SMOS grid-node. We also used other sites such as HOBE (Denmark), the two AMMA CATCH sites (Benin and Niger) and the Little Washita USDA watershed. For ECMWF, SMOS-L3, SMOS-NN, and the in situ data, the grid points were selected as follows: starting with the SMOS acquisition time, a time window of \pm 30 min was used to select one or two in situ measurements that would be compared to the remote sensing and model SM products. For AMMA, where in situ measurements are only available every three hours, the time window was increased to $\pm 90 \mathrm{~min}$. If more than one in situ measurement was found in that time window, they were averaged. Conditions of frozen soils $(T<274 \mathrm{~K})$ or soils covered by snow were filtered out using ECMWF model estimations of the soil temperature in the 0-7 cm layer and the snow depth. Finally, the only times for which the four (SMOSL3, SMOS-NN, ECMWF and in situ) soil moisture estimates were available were retained for computing the quality metrics.

Globally, the best results were obtained with SMOS with a few exceptions. Within the different SMOS approaches, the neural network gives similar results. Fig. 4 shows the percentage of cases where a given dataset gives best performances for each criterion. Detailed results are given in the Table A1 in the Appendix A.

\subsubsection{Sparse and dense networks: global statistical analysis}

The previous section discussed the comparison of common remote sensing products with respect to in situ measurements in details for a few sites. In the current section, only SMOS products are evaluated against in situ measurements but for a large number of sites worldwide (Table 2) and compared to ECMWF model simulations. Since L3 uses directly the L2 algorithm where the only difference is taking advantage of the multi temporal acquisitions, here we used the L3 only (see (Al Bitar et al., submitted for publication). For instance, using SMOS-L3 instead of SMOS-L2 does not drastically change results as shown in Fig. 2 (see also Appendix A). In addition, the SMOS-NN and the ECMWF IFS SM $(0-7 \mathrm{~cm})$ products are also evaluated.

For each in situ measurement site, the closest EASE grid point was selected, and then for this point the three SM products (SMOS-NN, SMOS-L3 and ECMWF) were compared to the in situ measurements. The results are from 9 November 2010 (so as to account for changes in ECMWF (see Section 3.3.2) to December 2013 (date for which V300 SMOS-L3 products are currently available)). The Pearson correlation coefficient (R), the standard deviation of the difference (STDE) with respect to the in situ measurements, and the bias were computed site per site using only times for which a soil moisture value was available for all four datasets. Afterwards, the results were analyzed by computing minimum and maximum values, 25th and 75th percentiles and the median. The final results are presented in the form of box plots in Figs. 5 to 7.

Fig. 5 summarizes the correlation, STDE and bias for all the in situ measurements sites as box plots both for ascending and descending overpasses. Even if there are small quantitative differences, qualitatively the three products show similar performances for both overpasses. The correlation is higher (and the STDE lower) for SMOS-NN and ECMWF. The two SMOS products together (SMOS-NN and SMOS-L3) are the closest to the reference (in situ measurements) in terms of bias.

A summary of the results in terms of R is given in Fig. 6 for the ascending orbits. The SMOS products (SMOS-NN, SMOS-L3) show better results in terms of correlation (R) (and bias not shown here) than ECMWF over 8 networks (out of a total of 13). However, one should bear in mind that ECMWF products used in this study have been spatially and temporally interpolated to the SMOS grid and overpass time, which could penalize the score of the ECMWF model simulations. The sites where SMOS-L3 performs better than ECMWF products are those
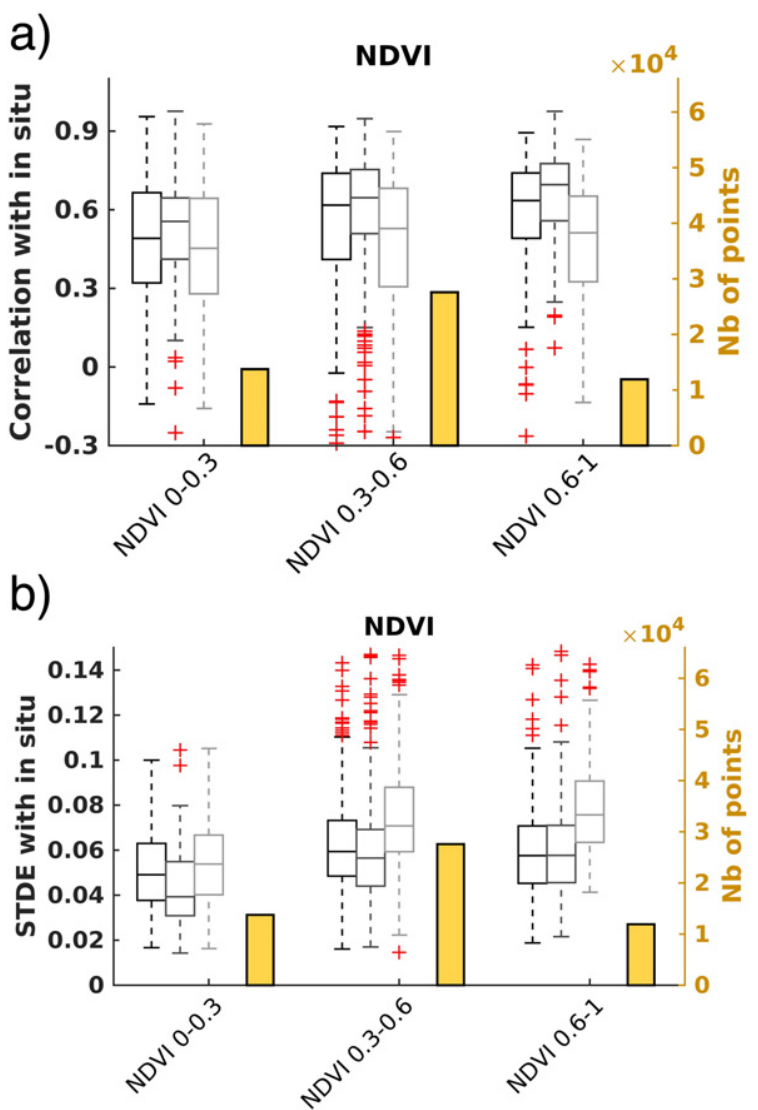

Fig. 7. Same as Fig. 5 but the statistics were computed as a function of the MODIS NDVI value. Only results for ascending overpasses are shown. Panel (a) Correlation. Panel (b): Standard deviation of the difference (STDE) with respect to the in situ time series.

mainly characterized by low vegetation and smooth topography: AMMA, ARM (0.05-0.05), DAHRA, PBO-H2O, OZNET (0-0.05), OZNET (0-0.08), LW and WG watersheds; conversely, for descending overpasses (not shown), SMOS-L3 has better results in terms of correlation (R) (and bias) than ECMWF for only 3 networks (LW, WG, and ARM (0.05-0.05)). While SMOS-NN shows larger median values of SM for 8 networks. The mean number of points for the times series of each network is given in Table 2 .

It is not straightforward to compare the results with those of previous global studies such as that of (Albergel et al., 2012) because the versions of the remote sensing data are not the same, and, mainly because the site selection is not done using the same protocol. Nevertheless, the results presented in the current study seem in overall good agreement with the mean values presented in Table 2 of Albergel et al. (2012).

These results can be analyzed further by considering different categories. In the following, the data were separated into categories based on NDVI, vegetation type, fraction of forest cover (\%), surface roughness and topography. Usual metrics ( $R$, STDE, Bias) were calculated for the time series (NN, ECMWF and L3 SM) at each in situ station location using the in situ data as a reference, and then averaged for the ensemble of locations per network (Fig. 6a). Results can be filtered according to the categories mentioned above (NDVI, vegetation type, fraction of forest cover (\%), etc).

Figs. 6 and 7a show the results in terms of values of the correlation coefficients (Pearson) for each category and for the three approaches (SMOS-NN, ECMWF and SMOS-L3) together with the population (number of points) for each category (however, one should bear in mind that the metrics are still computed site per site).

4.1.3.1. Surface roughness. In the present study, the effect of surface roughness was evaluated considering maps of the roughness parameter 
$\mathrm{Hr}$, used in the SMOS algorithm (Kerr et al., 2012), as computed by Parrens et al. (2014). Fig. 6d shows that the correlation coefficient decreases generally as the roughness parameter $\mathrm{Hr}$ increases (especially for SMOS-L3). For the higher values of surface roughness (Hr larger than 0.2 ), ECMWF performs slightly better than the other products in terms of correlation. For smooth and moderate roughness $(\mathrm{Hr} \sim 0.0-$ 0.2 ), the three products present similar results for ascending overpasses, though SMOS-NN provides better results in general. The results for descending orbits are similar (results not shown), but ECMWF exhibits slightly better correlations $\mathrm{R}$ than the SMOS retrievals for $\mathrm{Hr} \leq 0.1$.

4.1.3.2. Topography classes. The effects of topography were evaluated using the three classes (smooth, moderate, strong) considered in the SMOS algorithm (Kerr et al., 2012). In Fig. 6e, for smooth and strong topography, SMOS-NN is the best performing dataset in terms of correlation, for both ascending and descending (not shown) overpasses. However, for moderate topography, ECMWF achieves the best correlation. This may be explained by the characteristics of ground networks as described by Crow who showed that in some cases the ranking between approaches can be modified when the in situ measurement uncertainties are correctly accounted for (Crow et al., 2015).

4.1.3.3. Vegetation. Three main analyses were conducted: fraction of forest (\%), NDVI values, and vegetation types. The 16-day MODIS NDVI products (MOD13C1 and MYD13C1, version 600) were used to obtain values of the Normalized Difference Vegetation Index (NDVI) in the EASE grid (version 2) common to SMOS L3 products by aggregating the NDVI using a weighted mean with weights accounting for the SMOS antenna pattern which was approximated by a Gaussian beam with $43 \mathrm{~km}$ width at half maximum. The vegetation classification used is that of Matthews (1983).

For forest covered grid-nodes (Fig. 6b), it can be seen that for dense covers the ECMWF provides the best correlation coefficients while for medium and low forest fractions all three approaches give very similar results, SMOS-NN performing slightly better.

A second analysis on vegetation divides the dataset according to vegetation class (Fig. 6c). Sites characterized by forests (vegetation classes 1,2 and 3 ) and woodlands (vegetation classes 4 and 5) show better correlation for the ECMWF product, which is consistent with the previous analysis on forest fraction. For low vegetation classes (classes 6, 7, 9), SMOS-NN performs best. Obviously, this study will need to be done in more detail to ascertain whether such results are linked to the network representativeness or to the retrieval algorithms (Crow et al., 2015). It should be noted that for class 8 , corresponding to tundra, SMOS-L3 and SMOS-NN give very poor results, which can be easily explained by the specifics of such biomes. The low number of sites available (4) for this vegetation class makes any interpretation difficult at this stage and no conclusion can be drawn. However, it is worth investigating to investigate this further and currently studies are underway to better model such soil types (Bircher et al., 2014b).

Finally, Fig. 7 shows the results as a function of NDVI. Similarly to forests where correlation results do not depend significantly upon forest cover, the values of the correlation coefficient for the SMOS products do not depend significantly on NDVI. This is a confirmation of the results found by Al-Yaari, Wigneron, Ducharne, Kerr, de Rosnay, de Jeu, et al. (2014); Al-Yaari et al. (2014b), that the SMOS algorithm performs well in correcting for the effects of the vegetation opacity (parameterized here by the NDVI index) and that the time series capture the dynamics of the soil moisture signal well, even for high values of NDVI. However, the box plot for the STDE (Fig. 7b), shows that the STDE exhibits a trend to increase for NDVI $>0.3$, which implies that even if the temporal dynamics are on average well captured, there is more dispersion in the results for high NDVI values.

As a summary of this analysis based mainly on correlation values, it appears that the performance of the SMOS SM retrievals show a limited sensitivity to roughness effects (the quality of all SM products slightly decreases as roughness increases), and a low sensitivity to topography and vegetation effects. However, for high vegetation and forest density (e.g. for high NDVI values or forest fraction), ECMWF provides the best results.

Regarding the statistics per site (see Table A1 given in the Appendix A), the SMOS products (SMOS-NN, SMOS-L3) perform better than the ECMWF product for more sites for both ascending and descending orbits as shown on Fig 4. The sites where SMOS-L3 performs better than ECMWF products are those mainly characterized by low vegetation and smooth topography (AMMA-CATCH, ARM-0.5, DAHRA, OZNET, PBO, LW, and WG).

\subsection{Comparison at the global scale}

As a complement to the evaluation done with in situ measurements presented above, a global comparison between the SMOS-L3 and the AMSR2 soil moisture product (referred to as AMSR2-SM), described in Section 3.4.2.2 was made. Note that only the AMSR2 soil moisture products were considered here, as a detailed comparison study has already been made at global scale between the soil moisture products from SMOS, AMSR-E, and ASCAT in Al-Yaari, Wigneron, Ducharne, Kerr, de Rosnay, de Jeu, et al. (2014); Al-Yaari et al. (2014b). The MERRA-Land soil moisture product, described in Section 3.3.1, was used as a benchmark. The comparison period (07/2012-06/2014) was selected given the availability of both AMSR2 and SMOS soil moisture datasets. Note that due to a reprocessing campaign under way, all the SMOS-L3 are not available in the same version. The comparison was restricted to grid-nodes and dates where both SMOS-L3 and AMSR2-SM were available. Classical metrics (including correlation, bias, RMSD, and STDE) and the advanced triple colocation error method were used in this global comparison. It should be noted here that we used the term difference in RMSD rather than error (RMSE), as done in the local scale evaluation, because models cannot be considered as the ground truth, as mentioned earlier. Correlations were computed using original soil moisture values and anomalies that were computed following (Rüdiger et al., 2009).

$\mathrm{SM}_{\text {anomaly }}(\mathrm{t})=\frac{\mathrm{SM}(\mathrm{t})-\mathrm{SM}(\mathrm{t}-1 \overline{7}: \mathrm{t}+17)}{\sigma[\operatorname{SM}(\mathrm{t}-17: \mathrm{t}+17)]}$

where $\mathrm{SM}(\mathrm{t})$ is the original SM value at time $\mathrm{t}$, the over-bar is temporal mean, and $\sigma$ is standard deviation for a time window of 35 days defined by $\mathrm{t} \pm 17$ days.

The advanced triple colocation error method quantifies the spatial and temporal errors between three independent datasets (Stoffelen, 1998 ) and has been recently used in the soil moisture field (Al-Yaari et al., 2014b; Dorigo et al., 2010; Leroux, Kerr, Richaume, \& Fieuzal, 2013; Scipal, Holmes, de Jeu, Naeimi, \& Wagner, 2008). The triple collocation error method is described in (Draper et al., 2013).

\subsubsection{SMOS-L3 vs. AMSR2-SM results}

Fig 8a-j shows the spatio-temporal statistics between SMOS-L3 (left panels) and AMSR2-SM (right panels) soil moisture retrievals and the reference (MERRA-Land). These include (a\&b) correlation coefficients (R) computed using original values ( $p$-value $<0.01$ ), (c\&d) correlation coefficients (R) computed using anomalies ( $p$-value $<0.01$ ), (e\&f) bias $\left(\mathrm{m}^{3} / \mathrm{m}^{3}\right)$, (g\&h) RMSD $\left(\mathrm{m}^{3} / \mathrm{m}^{3}\right)$, and $(\mathrm{i} \& \mathrm{j})$ STDE $\left(\mathrm{m}^{3} / \mathrm{m}^{3}\right)$. In analyzing all these maps, it can be seen that the spatial patterns are generally similar for both SMOS-L3 and AMSR2-SM although there is a difference in magnitudes. SMOS-L3 is more consistent with the reference over most of the globe leading to higher correlations and lower RMSD and STDE values. This is particularly apparent over tundra and boreal regions where negative correlations and high RMSD and STDE values were generally obtained with AMSR2-SM. Both SMOS-L3 (more consistent with MERRA-Land) and AMSR2-SM generally lead to lower SM values than MERRA-Land. These lower soil moisture values (underestimating the 
(a) R (p-value < 0.01)_original

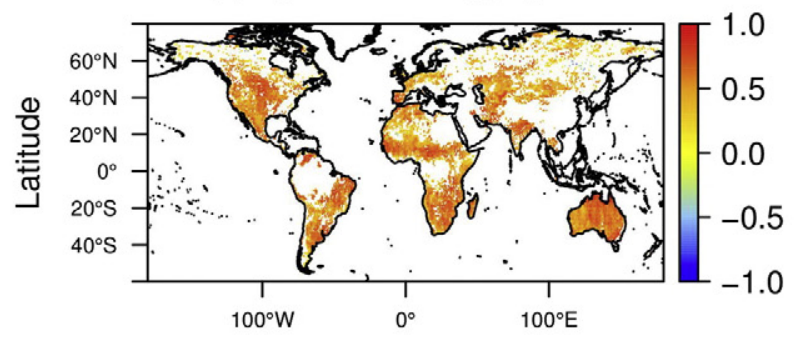

(c) R (p-value < 0.01)_anomaly

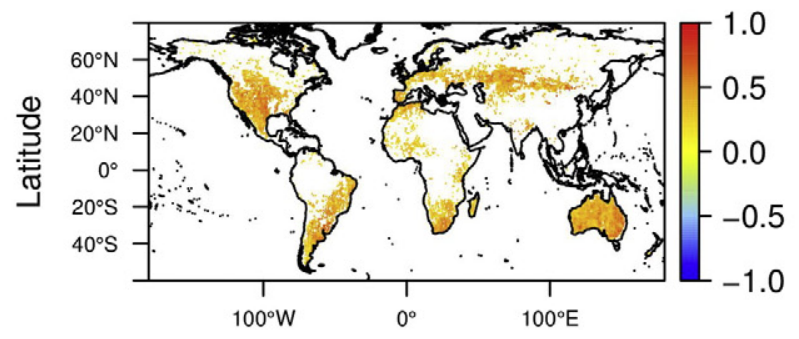

(e) Bias

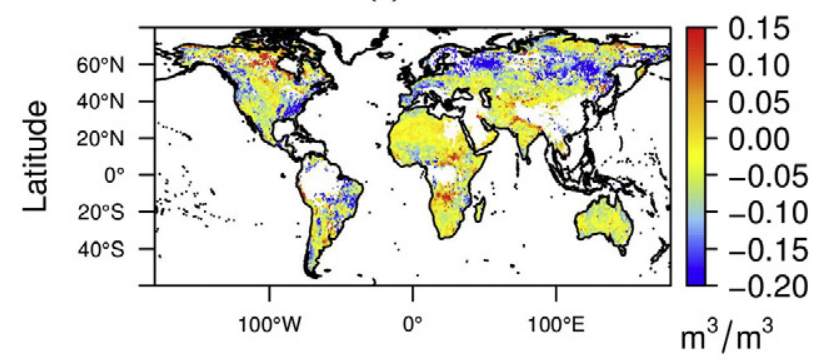

(g) RMSD

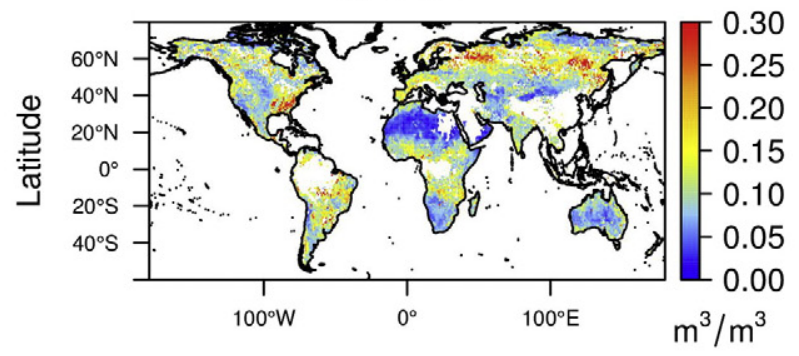

(i) STDE

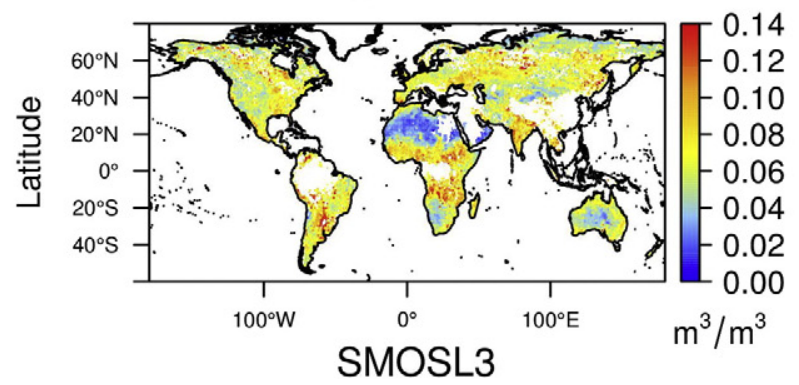

(b) R (p-value < 0.01)_original

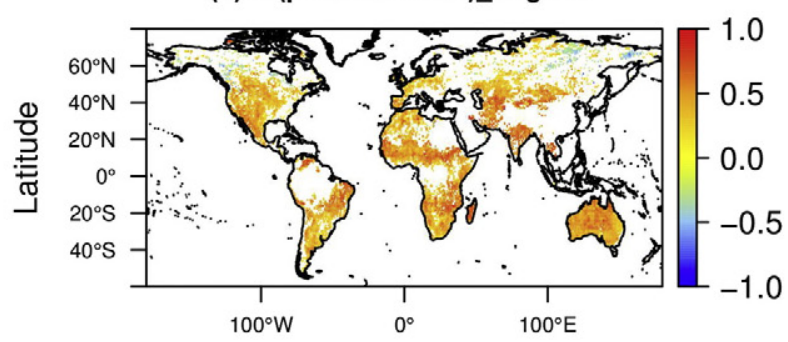

(d) R (p-value < 0.01)_anomaly

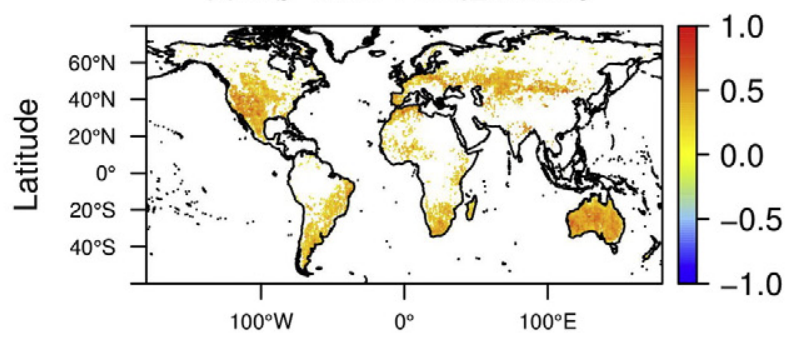

(f) Bias

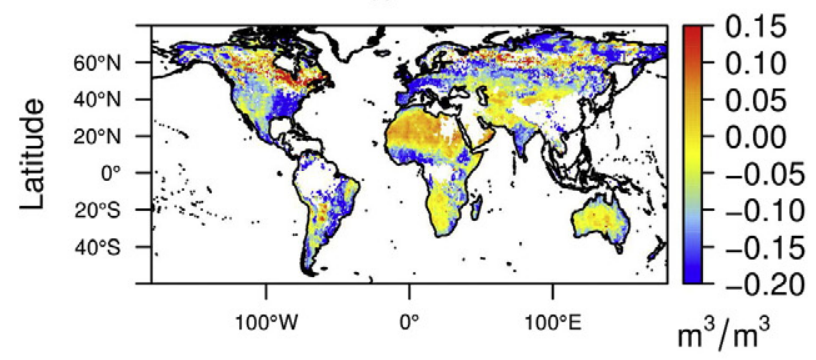

(h) RMSD

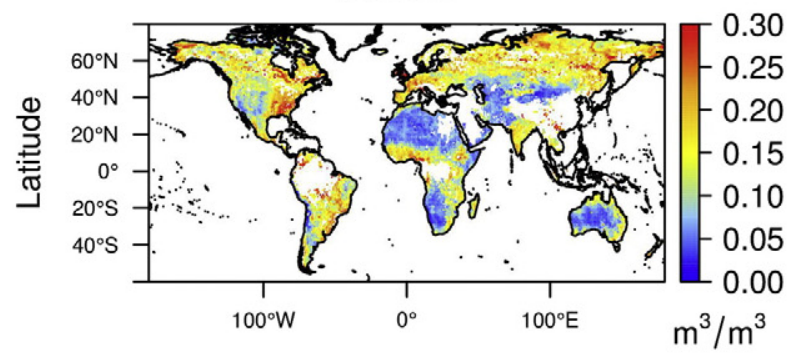

(j) STDE

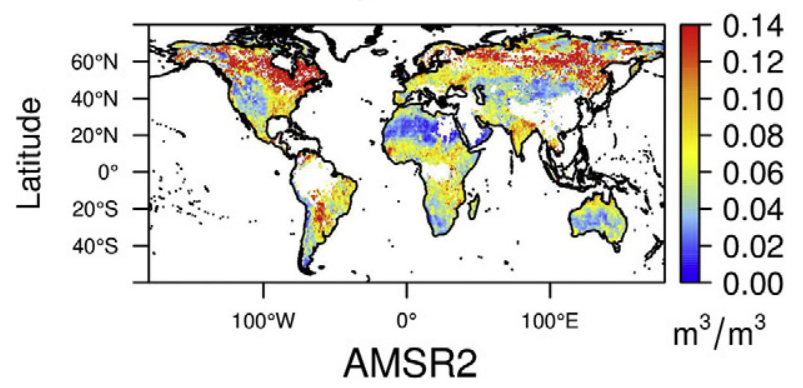

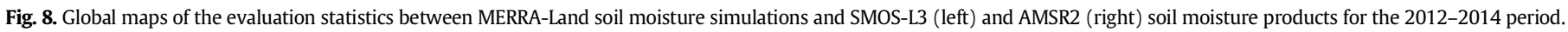

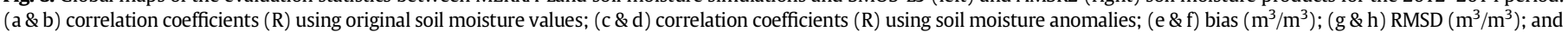
(i\& j) STDE $\left(\mathrm{m}^{3} / \mathrm{m}^{3}\right)$. 
reference) for both SMOS-L3 (Al-Yaari et al., 2014a) and AMSR2 (Kim et al., 2015) at global scale have been noted in previous studies. However, AMSR2-SM is wetter than the reference for the Sahara. This is in line with results presented by (Kim et al., 2015) who found that AMSR2-SM

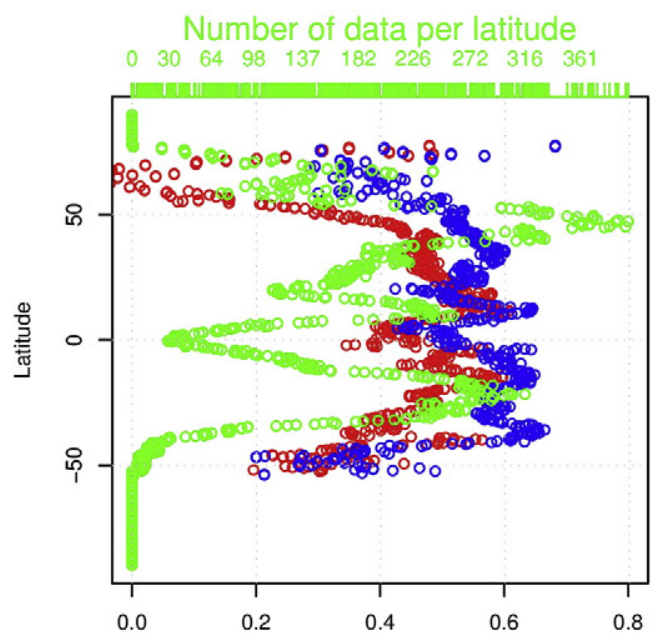

(a) Correlation with MERRA-Land_original

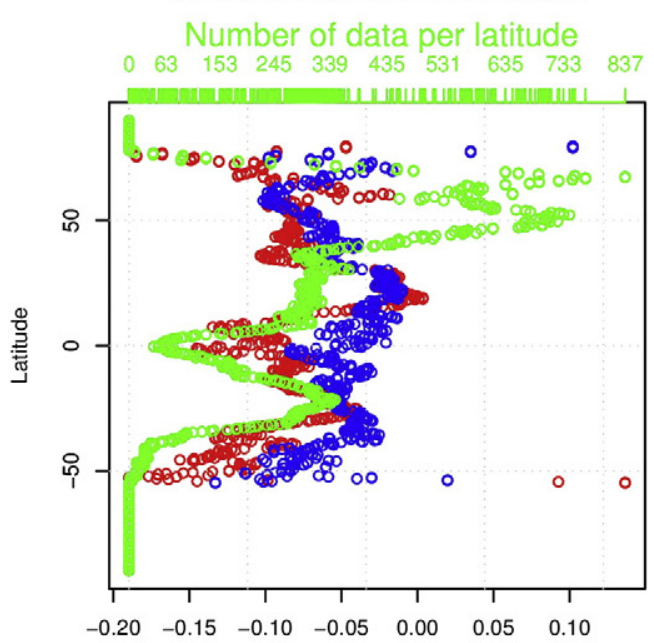

(c) $\operatorname{Bias}\left(\mathrm{m}^{3} / \mathrm{m}^{3}\right)$

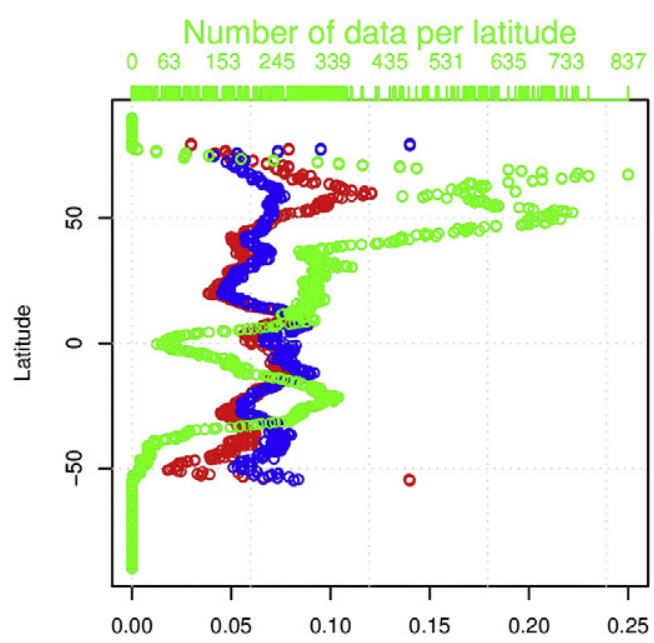

(e) $\operatorname{STDE}\left(\mathrm{m}^{3} / \mathrm{m}^{3}\right)$ provided high soil moisture values over some regions that are essentially very dry.

In order to get a different insight into the relative performances of AMSR2-SM and SMOS-L3 with respect to MERRA-Land estimates,
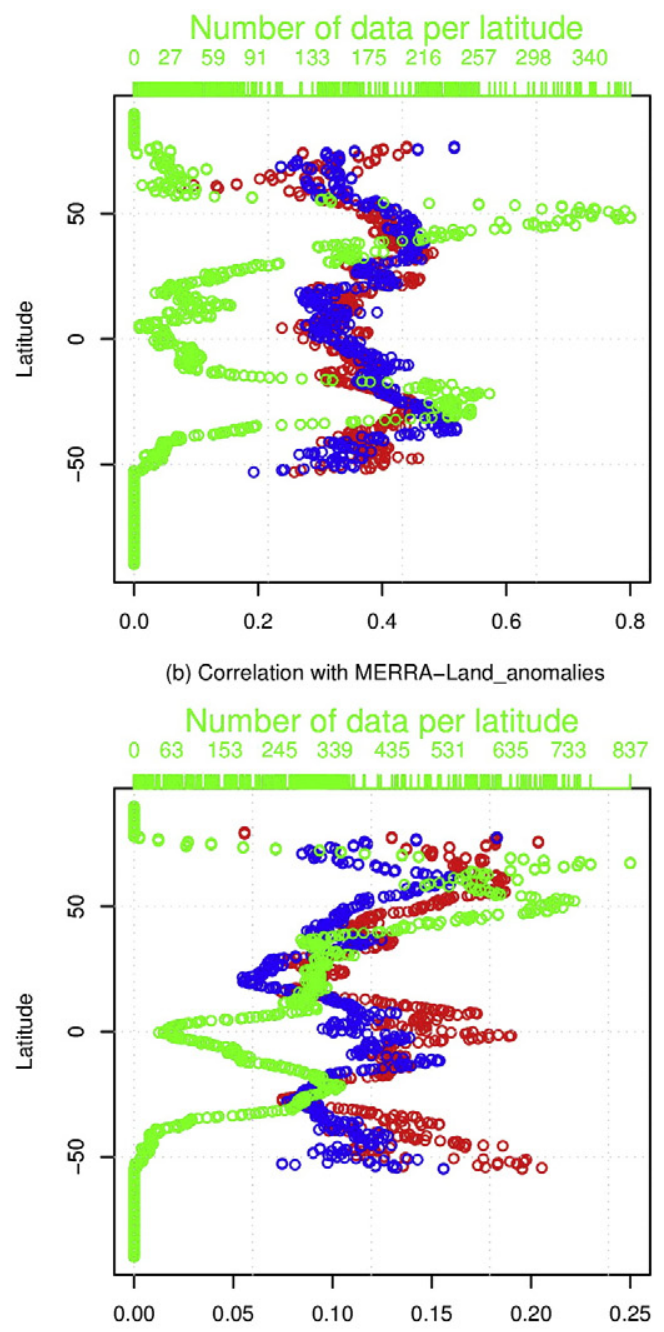

(d) $\operatorname{RMSD}\left(\mathrm{m}^{3} / \mathrm{m}^{3}\right)$

\section{Soil moisture product - SMOSL3 - AMSR2}

Fig. 9. Latitudinal means of (a) correlation coefficients (R) using original soil moisture values (b) correlation coefficients (R) using soil moisture anomalies; (c) bias ( $\left.\mathrm{m}^{3} / \mathrm{m}^{3}\right)$; $(\mathrm{d})$ RMSD $\left(\mathrm{m}^{3} / \mathrm{m}^{3}\right)$; and (e) STDE $\left(\mathrm{m}^{3} / \mathrm{m}^{3}\right)$ between AMSR2 (red) and SMOS-L3 (blue) soil moisture products against MERRA-Land soil moisture simulations. N is the number of data (green). 
latitudinal plots averaging these statistics and histograms considering the different land cover classes (Friedl et al., 2010) are presented in Fig. 9 and 12, respectively.

(a) Original
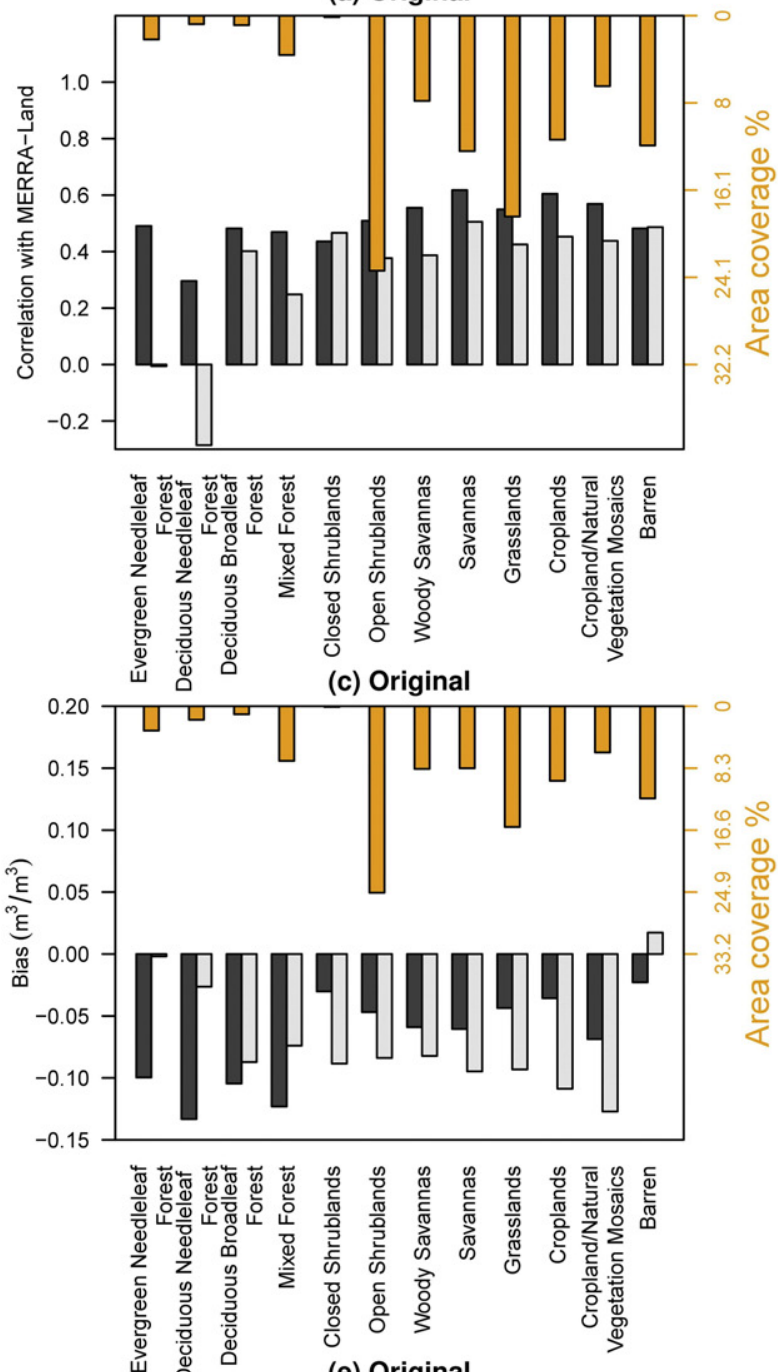

(e) Original

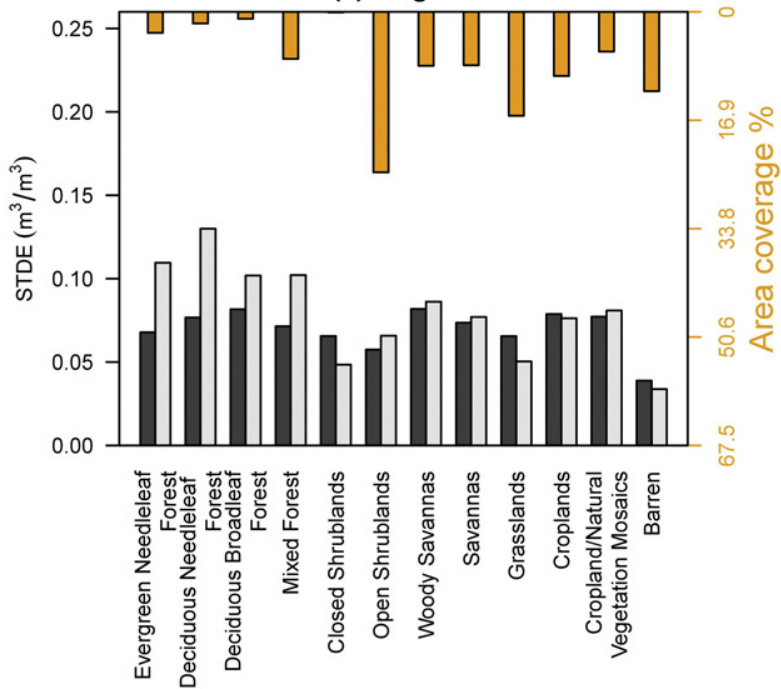

Fig 9 shows the latitudinal plots, which were produced taking the mean per latitude of each indicator used in Fig. 10: (a) correlation coefficients ( $R$ ) using original soil moisture values (b) correlation
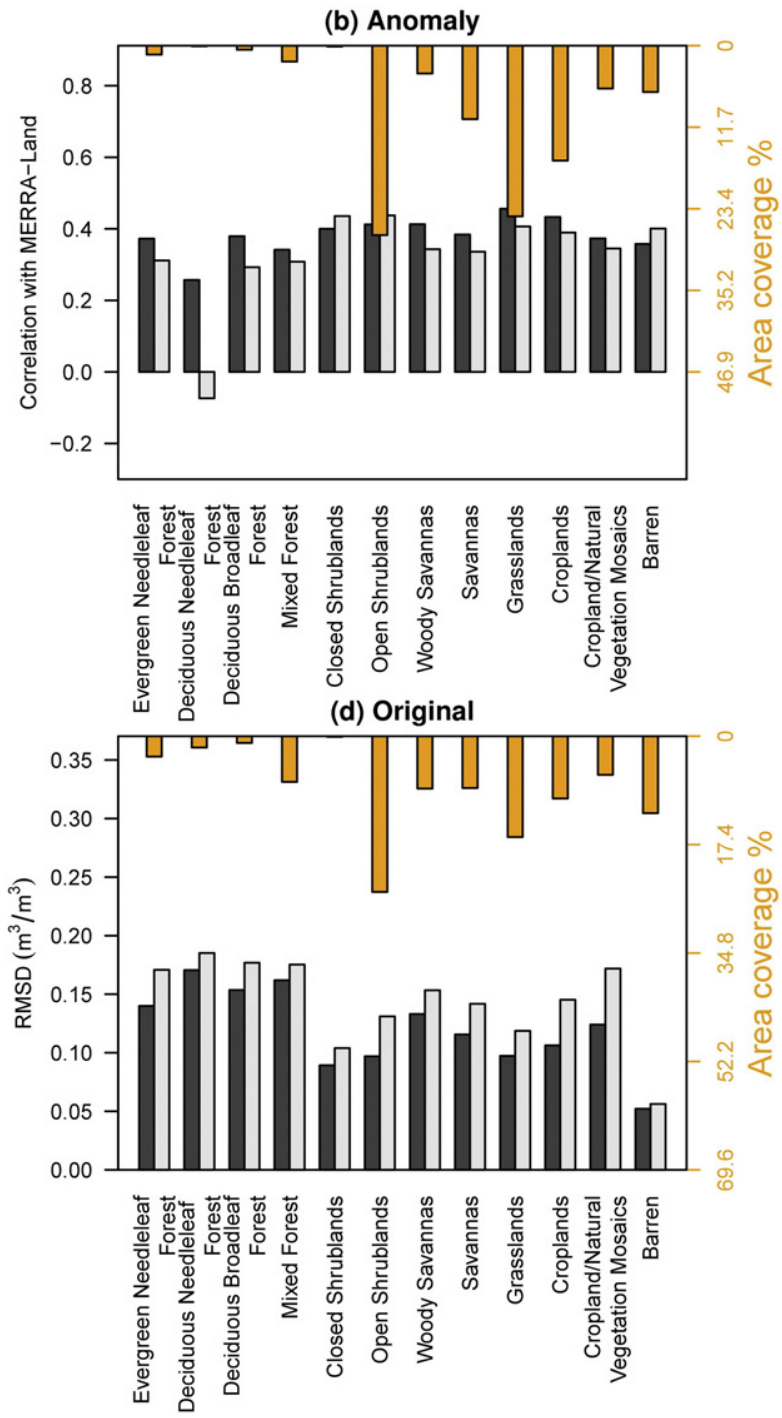

Soil moisture product

- SMOSL3 $\square$ AMSR2

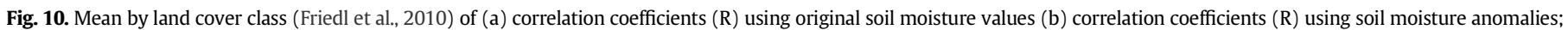
(c) bias $\left(\mathrm{m}^{3} / \mathrm{m}^{3}\right)$; (d) RMSD $\left(\mathrm{m}^{3} / \mathrm{m}^{3}\right)$; and (e) STDE $\left(\mathrm{m}^{3} / \mathrm{m}^{3}\right)$ between AMSR2 and SMOS-L3 soil moisture products against MERRA-Land soil moisture simulations. 
coefficients (R) using soil moisture anomalies; (c) bias $\left(\mathrm{m}^{3} / \mathrm{m}^{3}\right)$; (d) RMSD $\left(\mathrm{m}^{3} / \mathrm{m}^{3}\right)$; and (e) STDE $\left(\mathrm{m}^{3} / \mathrm{m}^{3}\right)$. It can be clearly noted that SMOS-L3 (blue) has higher correlations (particularly for original soil moisture), lower biases, and lower RMSD values than AMSR2-SM (red) for almost all latitudes when compared to MERRA-Land. Considering the STDE criteria, similar performances were generally obtained for both SMOS-L3 and AMSR2-SM for all latitudes, except that SMOS-L3 is slightly closer to MERRA-Land (lower STDE values) in the higher latitudes (Northern regions including boreal forests and tundra) while AMSR2-SM is slightly closer to MERRA-Land in arid areas of the Southern hemisphere (South Africa, Australia, South of Argentina and Chile).

Fig. 10a-e shows the mean by land cover class (Friedl et al., 2010) of the (a) correlation coefficients (R) using original soil moisture values (b) correlation coefficients (R) using soil moisture anomalies (c) bias $\left(\mathrm{m}^{3} / \mathrm{m}^{3}\right)$ (d) RMSD $\left(\mathrm{m}^{3} / \mathrm{m}^{3}\right)$ and (e) STDE $\left(\mathrm{m}^{3} / \mathrm{m}^{3}\right)$. As can be seen in Fig. 10, there is in general a higher consistency between SMOS-L3 (black) and the reference than for AMSR2-SM (gray) over the forests and regions with dense vegetation (e.g. Evergreen Needle-leaf Forests, Deciduous Needle-leaf Forests, Deciduous Broadleaf Forests, Mixed Forests) for all metrics, except for bias. Considering bias over these canopy types, there is a larger difference (lower values) between MERRALand SM data and SMOS-L3 than with AMSR2-SM. In Fig. 10d (RMSD criterion), it can be seen that SMOS was closer to MERRA-Land for all land cover classes.

If we exclude the regions with forests and dense vegetation, the SMOS-L3 SM and AMSR2-SM products are similar over all land cover classes for the correlation coefficient computed from anomalies (Fig. 11b) and for the STDE indicator (Fig. 10e) when compared to MERRA-Land.

Fig. 11 shows the spatial errors $\left(\mathrm{m}^{3} / \mathrm{m}^{3}\right)$ estimated using the triple collocation method. In general, the errors are relatively low for both
SMOS-L3 and AMSR2-SM (global average values are $0.023 \mathrm{~m}^{3} / \mathrm{m}^{3}$ and $0.031 \mathrm{~m}^{3} / \mathrm{m}^{3}$ for SMOS-L3 and AMSR2-SM, respectively). The spatial patterns are in agreement with the land cover types with higher errors over vegetated regions and lower values over deserts. These two maps confirm the previous results obtained using the classical metrics: AMSR2-SM has higher (than SMOS-L3) spatial errors over the regions where the vegetation is dense or moderate (e.g. tropics, boreal regions, eastern USA and Canada, south-eastern Australia and most of the continent of South America).

The spatial errors shown in the two maps in Fig. 11a-b were averaged as a function of land cover classes (Friedl et al., 2010) and are shown in Fig. 12. There is a higher consistency between SMOS-L3 (black) and the reference than for AMSR2-SM (gray) over most of the land cover classes (e.g. Evergreen Needle leaf Forests, Deciduous Broadleaf Forests, Mixed Forests, Woody Savannas, Savannas, Grasslands, Croplands, Cropland/Natural Vegetation Mosaics). There are two main exceptions: comparable performances are obtained for SMOS-L3 and AMSR2-SM over open shrub lands which represent almost 30\% of the global land area coverage and there is a higher consistency between AMSR2-SM and the reference over Barren (sparse vegetation) regions, which represent almost $10 \%$ of the area coverage.

\subsubsection{Discussion}

Considering the global analysis presented in the previous section (Figs. 8 to 12), SMOS-L3 was found to be more consistent to the reference than AMSR2-SM, in particular over the regions where the vegetation is dense or moderate. This result confirmed previous findings that compared SMOS-L3 to soil moisture products derived from AMSR-E (the predecessor of AMSR2). For instance, Al-Yaari et al. (2014a) compared SMOS-L3 soil moisture products with soil moisture derived from the AMSR-E observations and found that the former was closer to the

(a) SMOSL3

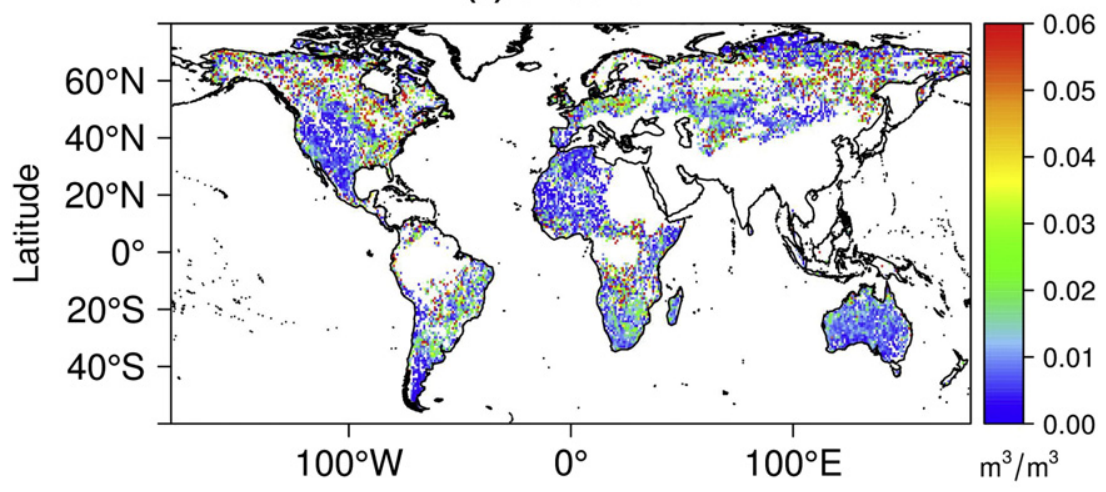

(b) AMSR2

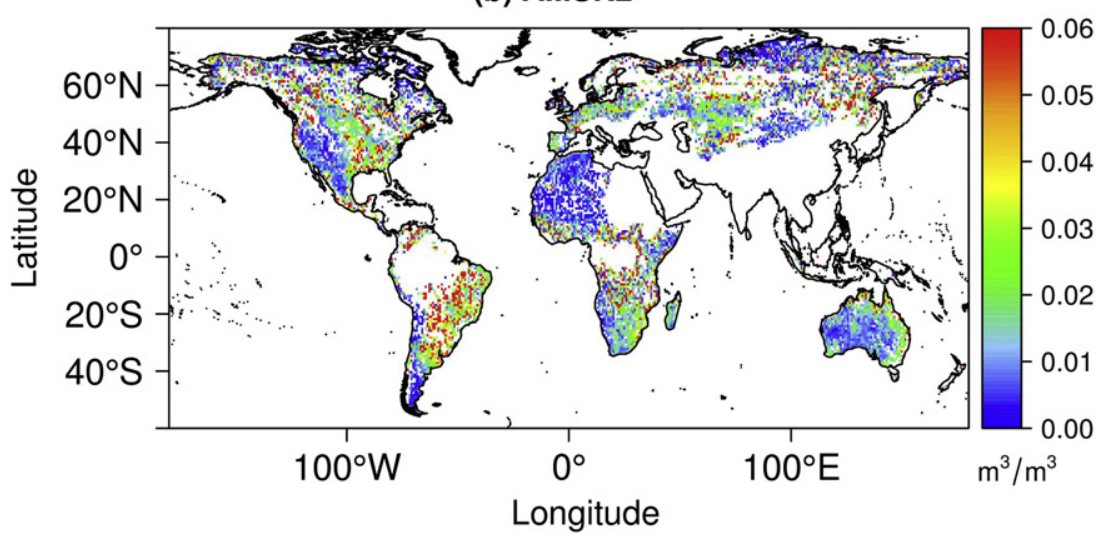

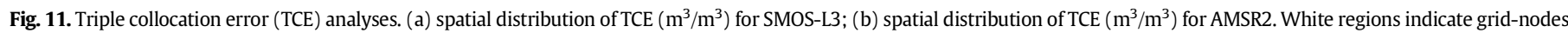
with $<100$ observations common to both SMOS-L3 and AMSR2-SM. 


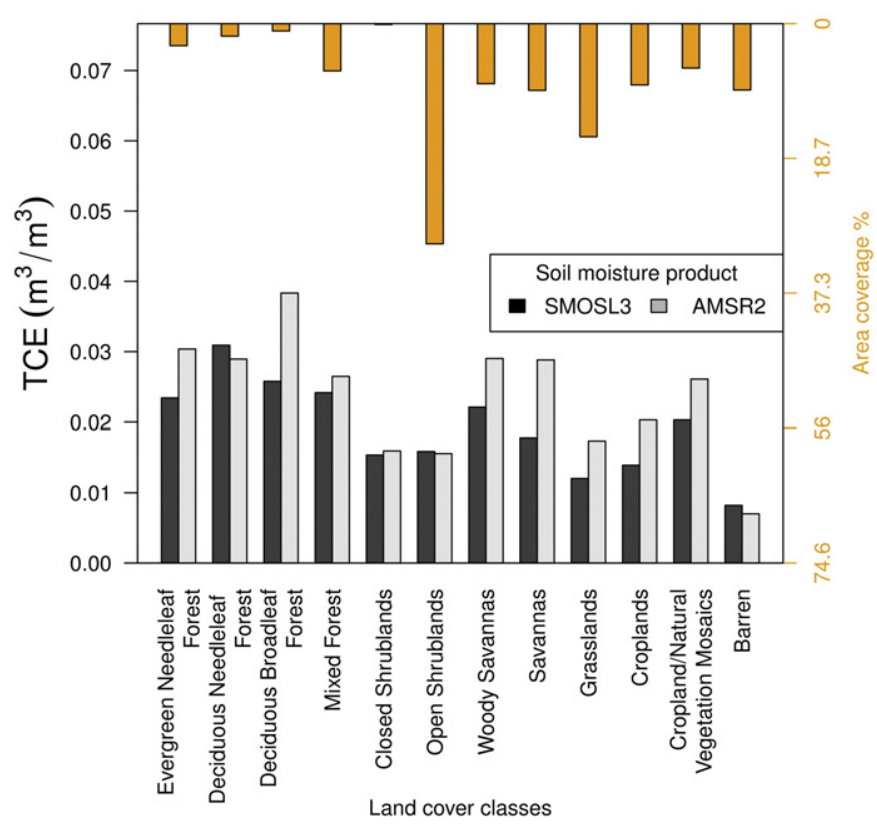

Fig. 12. Mean by land cover class (Friedl et al., 2010) of the triple collocation errors $\left(\mathrm{m}^{3} / \mathrm{m}^{3}\right)$ between AMSR2 (gray) and SMOS-L3 (black) soil moisture products against MERRA-Land soil moisture simulations.

reference particularly over vegetated regions. This is not surprising given that SMOS operates at L-band $(1.4 \mathrm{GHz})$ which is considered to be less affected by the attenuation effects of the vegetation canopies than higher frequencies such as the C- and X-bands used by AMSR2 (de Jeu et al., 2008; Jackson \& Schmugge, 1989; Kerr et al., 2001; Ulaby, Moore, \& Fung, 1981).

On the other hand, comparable results for SMOS-L3 and AMSR2-SM were found over closed and open shrub lands and AMSR2-SM was closer than SMOS-L3 to the modeled reference over barren regions for most of the analyses when models are often too wet over dry areas (in total these two land cover classes represent almost 30\% of the global land area coverage). Moreover, it seems that the specific approach used in the JAXA algorithm over dry regions (i.e. a four stream fast model) led to improved soil moisture retrievals over these regions (Kim et al., 2015). It is worth noting too that MERRA-Land may not represent well the truth in regions that lack precipitation gauges (Al-Yaari et al., 2014b), which might have an impact on the performance evaluation of both AMSR2-SM and SMOS-L3.

The Dobson dielectric mixing model (Dobson, Ulaby, Hallikainen, \& Elrayes, 1985) was replaced by the Mironov model (Mironov, Kosolapova, \& Fomin, 2009) in the latest reprocessed version of SMOS-L3 which is considered here. The Mironov model generally leads to higher soil moisture values in the SMOS-L3 at global scale, but there is a large variability in this result from one region to another (Mialon et al., 2015). The results shown in Fig. 9e-f indicate that SMOS-L3 is still drier than the reference mainly over tundra, eastern USA, Brazil, and Europe. Nevertheless, it can be seen that SMOS-L3 is wetter than the reference over a few regions (regions close to the equator in Africa). Al-Yaari, Wigneron, Ducharne, Kerr, de Rosnay, de Jeu, et al. (2014); Al-Yaari et al. (2014b) demonstrated that the earlier version of the SMOS-L3 soil moisture product, using the Dobson model was drier than MERRA-Land over most of the globe. The present global study confirms that there is a positive or a negative

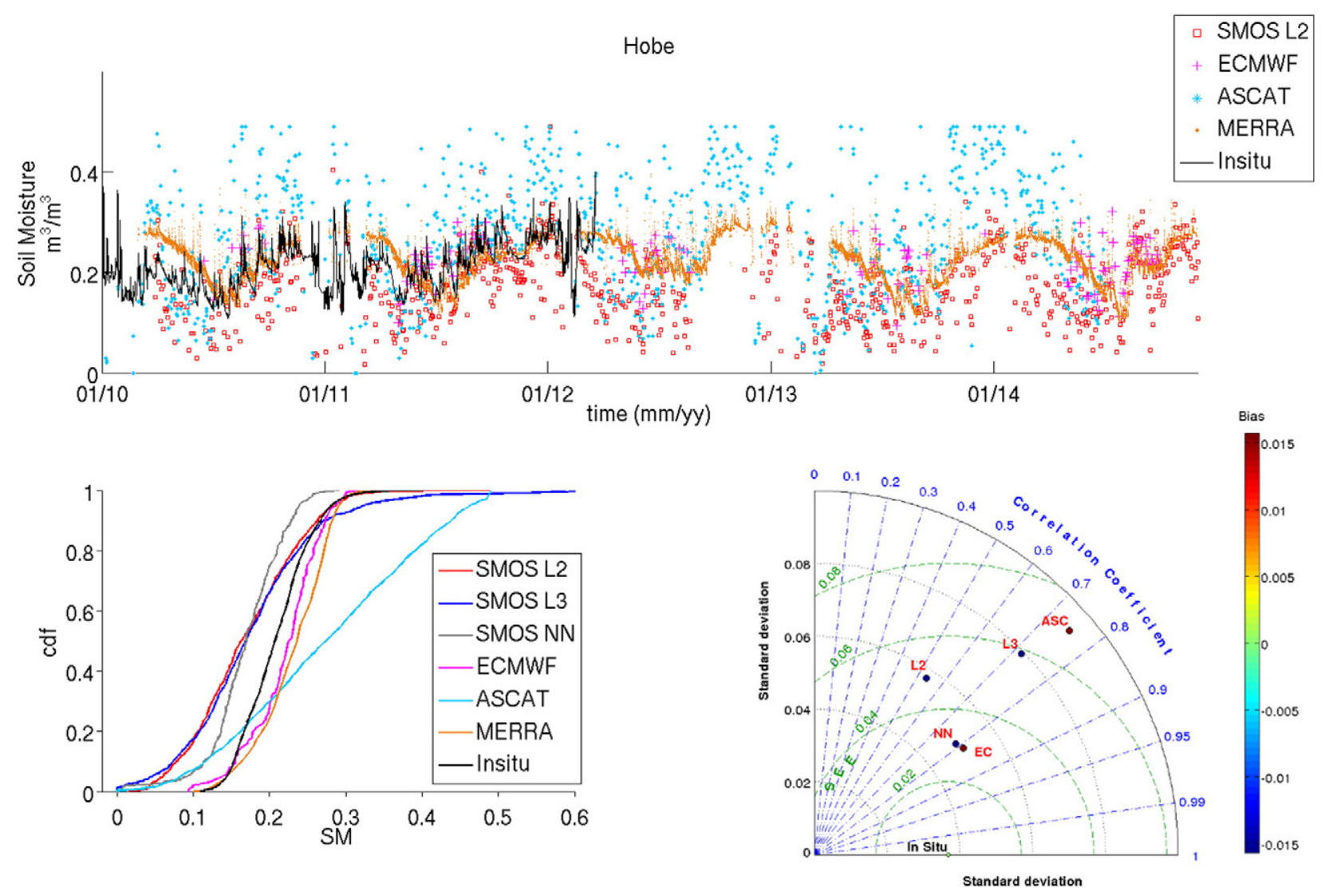

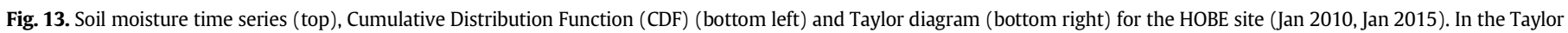
Diagram, ASC, L2, L3, NN, EC stands respectively for ASCAT, SMOS-L2, SMOS-L3, SMOS-NN and ECMWF). 
difference with MERRA-Land, depending on the region. Introducing the Mironov model instead of the Dobson model in the algorithm improved results when compared to the dense network or sparse network databases.

\section{Overall discussion}

The first conclusion from our analysis is that there is a strong need for a) a set of consistent metrics and b) a better way to qualify the ground data which also have their own imperfections.

To illustrate the first point, Figs. 13 to 15 depicts three different cases. SMOS L2 soil moisture (SMOS-L2) is depicted in the time series (top of Figs. 13 to 15), but note that for the sake of clarity not all the temporal series are plotted. However, SMOS-L3 and SMOSNN are also displayed as Cumulative Distribution Function (CDF) to be compared to all the datasets (bottom left of Figs. 13 to 15). These examples illustrate the fact that at least three different types of metrics are required to correctly evaluate and compare different SM datasets. Taylor diagrams show how the datasets statistically compare between them and to ground measurements, temporal plots show how they capture temporal evolution of SM while CDF plots $t$ can be used to compare the range of values from different SM products.

The HOBE site (Fig. 13) is difficult to interpret as RFI levels are high and it is surrounded by seas. The temporal plots exhibit many oscillations for the satellite data and in particular for ASCAT and to a lesser degree for SMOS. MERRA-Land is much smoother than even ECMWF. However, the Taylor diagram shows that where SMOS-L2, SMOS-L3 and ASCAT provide rather poor results, the SMOS-NN approach represents SM well in this difficult environment and behaves slightly better than ECMWF. Note also that if adequately filtered of RFI sources,
SMOS-L2 and SMOS-L3 results improve significantly (Bircher et al., 2013). The CDF plots are also very instructive as they show that the distribution of soil moisture is not equivalent for all SM products. For instance, ASCAT has a quasi linear progression.

Another example is shown in Fig. 14 for the AMMA-CATCH site in Niger (Jan 2010-Jan 2014). The AMSR-E SM data (up to October 2011) seem to be fixed at a very dry level during the whole dry season, while MERRA-Land and ECMWF never get as dry (visible from the CDF plots). SMOS-L2 follows the ground measurements quite well with the exception of "peaks" during the wet season which are attributed to ponding effects, also visible on AMSR data. ASCAT SM values start to increase with vegetation and not with the first rains. They remain relatively high during most of the dry season and fall back to very low values shortly before the onset of the following rainy season. CDF curves do depict these behaviors quite well.

Finally, in Fig. 15, very variable soil moisture signals can be seen over Rogers's farm, a SCAN site. AMSR-E has a tendency to produce low values that are often not very realistic, and are also depicted on the CDF curves. MERRA-Land and ECMWF start with high soil moisture values but MERRA-Land SM values have a much smaller range and less variation, which could be considered as strange as its layer depth is only $2 \mathrm{~cm}$ vs $7 \mathrm{~cm}$ for ECMWF. The CDF curves for SMOS (SMOS-L2, SMOS-L3 and SMOS-NN) are quite close to the in situ one while ASCAT show a low correlation. For this case also, SMOS-NN seems to give the best results.

\section{Conclusions and perspectives}

The study presented here aimed at evaluating the performances of the SMOS products on three different levels: a) in terms of product

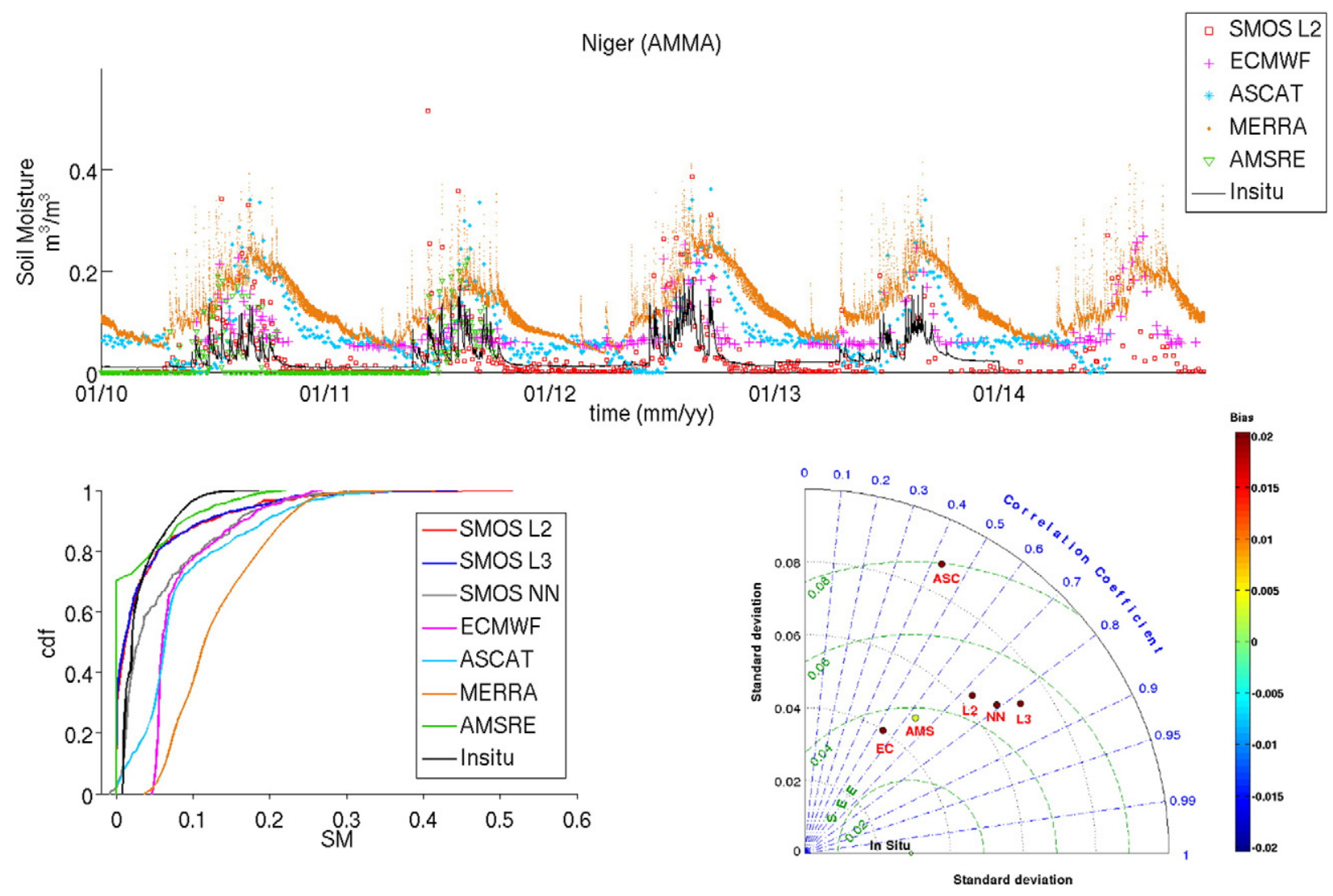

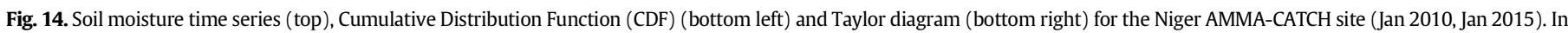
the Taylor Diagram, ASC, AMS, L2, L3, NN, EC stands respectively for ASCAT, AMSR-E, SMOS-L2, SMOS-L3, SMOS-NN and ECMWF). 


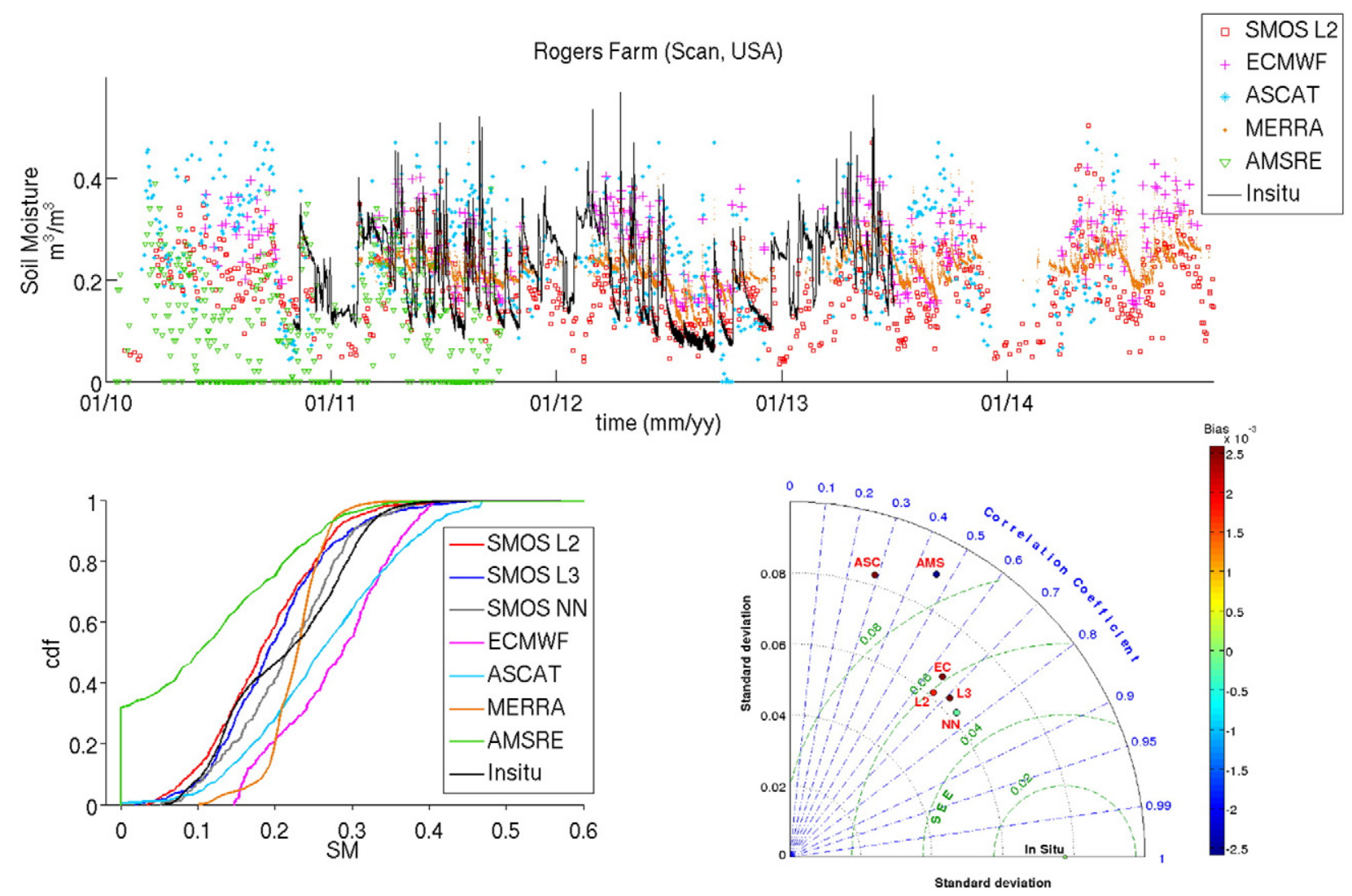

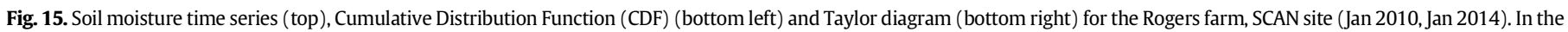
Taylor Diagram, ASC, AMS, L2, L3, NN, EC stands respectively for ASCAT, AMSR-E, SMOS-L2, SMOS-L3, SMOS-NN and ECMWF).

evolution (from V551 to V620), b) in terms of different products (SMOS-L2, SMOS-L3 and SMOS-NN) and c) in terms of comparison with other soil moisture products. Different datasets were used that ranged from well-equipped and maintained sites (the dense networks), to large scale sets of sites (sparse networks), model outputs and soil moisture products from other sensors.

It is difficult to draw definitive conclusions until better metrics and approaches are defined and adopted by the community. Therefore, all commonly used approaches were employed in this study. The next step will be to better ascertain the quality of the so called ground data and other SM references (Crow et al., 2015).

From this study it was found that the new SMOS L2 algorithm, V620, delivered much better results than the previous version, V551. Some cases are still not satisfactory but first analyses tended to show that the land use map currently used in the SMOS algorithm may be a cause for errors, in some areas. This work is in progress.

The analysis of the other SMOS products such as L3 soil moisture from CATDS (SMOS-L3) and SMOS-NN, produced from the neural network algorithm currently implemented at ECMWF, are also very encouraging. The latter gives excellent results and often yields better estimates than the more classical products. These good results may lead to a very efficient approach to provide near real time soil moisture products and could be one way to achieve a seamless transition between soil moisture sensors from the past (AMSR-E, Scanning Multi Channel Microwave Radiometer (SMMR)) and the future (AMSR2, SMAP) to make a long term soil moisture data records (RodriguezFernandez et al., 2015).

When compared to other model or satellite products it was found that SMOS is more consistent globally and often gives the best results. It does not exhibit anomalous wet values over dry areas and seems to be relatively insensitive to vegetation density (parameterized here by the NDVI index). Over forested areas, some progress has been made (even though, before launch, it was not expected to achieve results with SMOS for high biomass levels).

There are still some issues to be resolved though. The most pressing one is related to RFI. Even though the number of sources has generally decreased, some threats are still present. Once properly filtered, some data can still be used but with degraded performances. More recent sensors such as SMAP capitalized on SMOS early observations to develop a very sophisticated RFI detection approach, enabling it to extend the range for useful TB values in the presence of RFI (spectrogram analysis). Nevertheless, performances are obviously reduced when RFI is present and there are still significant regions of the world where no retrievals are possible. Another issue is related to the auxiliary files used to describe land use. It was found that the one used for SMOS (ECOCLIMAP) was not adequate in some parts of the world. Hence, the use of other maps (IGBP for instance) can improve - in some cases - the results. Future studies will be devoted to finding an optimal map describing land use at global scale in the SMOS algorithm.

\section{Acknowledgments}

The authors are very grateful to all the teams dedicating time to collect ground data and to quality check them before making them available. Authors are also very grateful to all data users who provide feedback on data quality through their own Cal Val activities, enabling us to improve our products. The authors also wish to thank the reviewers for their very useful and in depth comments. Finally the authors wish to thank CNES who funds the CATDS activities as well as science through the TOSCA program. 
Table A1

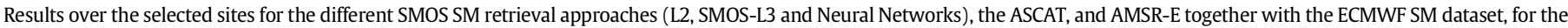
period of June 2010 to June 2012 and separated between morning and afternoon orbits. Results with $p$-values $>0.01$ are left blank.

\begin{tabular}{|c|c|c|c|c|c|c|c|c|}
\hline \multirow{2}{*}{ Data } & Bias & RMSE & $\mathrm{R} 2$ & std & Bias & RMSE & $\mathrm{R} 2$ & std \\
\hline & \multicolumn{4}{|l|}{ Ascending } & \multicolumn{4}{|c|}{ Descending } \\
\hline SCAN & 2018 & Torrington & & & & & & \\
\hline SMOS-L3 & - & - & - & - & 0.005 & 0.046 & 0.23 & 0.052 \\
\hline ECMWF & - & - & - & - & - & - & - & - \\
\hline SMOS-NN & 0.006 & 0.045 & 0.19 & 0.047 & -0.001 & 0.042 & 0.26 & 0.048 \\
\hline ASCAT & 0.066 & 0.074 & 0.47 & 0.039 & 0.057 & 0.065 & 0.36 & 0.037 \\
\hline SMOS-L2 & 0.017 & 0.037 & 0.39 & 0.038 & 0.019 & 0.047 & 0.33 & 0.053 \\
\hline AMSR-E & 0.094 & 0.101 & 0.35 & 0.042 & 0.097 & 0.104 & 0.46 & 0.049 \\
\hline SCAN & 2093 & Phillipsburg & & & & & & \\
\hline SMOS-L3 & 0.015 & 0.054 & 0.55 & 0.078 & 0.018 & 0.045 & 0.71 & 0.077 \\
\hline ECMWF & 0.078 & 0.096 & 0.41 & 0.068 & 0.072 & 0.085 & 0.59 & 0.069 \\
\hline SMOS-NN & -0.003 & 0.034 & 0.71 & 0.056 & -0.001 & 0.03 & 0.77 & 0.063 \\
\hline ASCAT & 0.048 & 0.084 & 0.28 & 0.08 & 0.035 & 0.07 & 0.33 & 0.072 \\
\hline SMOS-L2 & -0.015 & 0.046 & 0.58 & 0.064 & -0.013 & 0.036 & 0.67 & 0.052 \\
\hline AMSR-E & 0.078 & 0.101 & 0.16 & 0.058 & 0.093 & 0.118 & 0.17 & 0.071 \\
\hline SCAN & 2001 & Rogers Farm & & & & & & \\
\hline SMOS-L3 & -0.001 & 0.054 & 0.52 & 0.068 & 0.007 & 0.052 & 0.56 & 0.062 \\
\hline ECMWF & 0.054 & 0.082 & 0.4 & 0.071 & 0.062 & 0.087 & 0.42 & 0.066 \\
\hline SMOS-NN & -0.002 & 0.047 & 0.62 & 0.07 & -0.037 & 0.065 & 0.52 & 0.056 \\
\hline ASCAT & - & - & - & - & 0.051 & 0.097 & 0.22 & 0.075 \\
\hline SMOS-L2 & 0.001 & 0.057 & 0.47 & 0.069 & -0.009 & 0.054 & 0.59 & 0.041 \\
\hline AMSR-E & -0.097 & 0.124 & 0.32 & 0.09 & -0.118 & 0.15 & 0.18 & 0.084 \\
\hline SCAN & 2030 & UAPBL & Loneke Farm & & & & & \\
\hline SMOS-L3 & -0.01 & 0.043 & 0.59 & 0.058 & 0.023 & 0.073 & 0.27 & 0.071 \\
\hline ECMWF & 0.044 & 0.067 & 0.45 & 0.062 & 0.04 & 0.082 & 0.18 & 0.063 \\
\hline SMOS-NN & -0.012 & 0.046 & 0.51 & 0.044 & 0.004 & 0.062 & 0.22 & 0.035 \\
\hline ASCAT & -0.088 & 0.103 & 0.35 & 0.063 & -0.083 & 0.106 & 0.27 & 0.065 \\
\hline SMOS-L2 & -0.015 & 0.054 & 0.41 & 0.06 & -0.005 & 0.068 & 0.19 & 0.055 \\
\hline AMSR-E & - & - & - & - & - & - & - & - \\
\hline SCAN & 2168 & Jornada & Exp Range & & & & & \\
\hline SMOS-L3 & 0.051 & 0.078 & 0.49 & 0.074 & - & - & - & - \\
\hline ECMWF & SM & 0.127 & 0.168 & 0.3 & 0.121 & - & - & - \\
\hline SMOS-NN & 0.056 & 0.077 & 0.49 & 0.068 & - & - & - & - \\
\hline ASCAT & - & - & - & - & - & - & - & - \\
\hline SMOS-L2 & 0.034 & 0.049 & 0.29 & 0.04 & - & - & - & - \\
\hline AMSR-E & 0.006 & 0.027 & 0.33 & 0.032 & - & - & - & - \\
\hline SCAN & 2079 & Mammoth & Cave & & & & & \\
\hline SMOS-L3 & -0.079 & 0.095 & 0.69 & 0.076 & -0.036 & 0.089 & 0.44 & 0.103 \\
\hline ECMWF & 0.192 & 0.201 & 0.67 & 0.049 & 0.217 & 0.228 & 0.5 & 0.05 \\
\hline SMOS-NN & -0.09 & 0.103 & 0.72 & 0.065 & -0.03 & 0.062 & 0.68 & 0.084 \\
\hline ASCAT & 0.178 & 0.186 & 0.26 & 0.051 & 0.012 & 0.079 & 0.35 & 0.042 \\
\hline SMOS-L2 & -0.088 & 0.098 & 0.8 & 0.082 & -0.037 & 0.063 & 0.73 & 0.092 \\
\hline AMSR-E & 0.094 & 0.143 & 0.36 & 0.129 & -0.062 & 0.117 & 0.44 & 0.132 \\
\hline SCAN & 2160 & Grouse & Creek & & & & & \\
\hline SMOS-L3 & 0.039 & 0.052 & 0.53 & 0.044 & 0.053 & 0.074 & 0.58 & 0.075 \\
\hline ECMWF & 0.074 & 0.08 & 0.61 & 0.042 & 0.085 & 0.094 & 0.85 & 0.072 \\
\hline SMOS-NN & 0.028 & 0.04 & 0.49 & 0.037 & 0.047 & 0.055 & 0.64 & 0.05 \\
\hline ASCAT & - & - & - & - & 0.046 & 0.063 & 0.52 & 0.061 \\
\hline SMOS-L2 & 0.026 & 0.033 & 0.52 & 0.029 & 0.049 & 0.057 & 0.68 & 0.05 \\
\hline AMSR-E & 0.089 & 0.099 & 0.27 & 0.051 & 0.157 & 0.162 & 0.64 & 0.067 \\
\hline SCAN & 2024 & Goodwin & Creek & Pasture & & & & \\
\hline SMOS-L3 & -0.098 & 0.111 & 0.58 & 0.08 & -0.115 & 0.124 & 0.6 & 0.069 \\
\hline ECMWF & 0.054 & 0.087 & 0.21 & 0.056 & 0.057 & 0.078 & 0.41 & 0.057 \\
\hline SMOS-NN & -0.07 & 0.085 & 0.59 & 0.067 & -0.137 & 0.143 & 0.61 & 0.057 \\
\hline ASCAT & -0.145 & 0.157 & 0.39 & 0.063 & -0.136 & 0.153 & 0.19 & 0.062 \\
\hline SMOS-L2 & -0.1384 & 0.146 & 0.61 & 0.066 & -0.126 & 0.136 & 0.45 & 0.058 \\
\hline AMSR-E & - & - & - & - & - & - & - & - \\
\hline SCAN & 2053 & WTARS & & & & & & \\
\hline SMOS-L3 & 0.011 & 0.107 & 0.42 & 0.06 & 0.015 & 0.082 & 0.58 & 0.08 \\
\hline ECMWF & 0.223 & 0.248 & 0.42 & 0.056 & 0.236 & 0.254 & 0.44 & 0.066 \\
\hline SMOS-NN & -0.036 & 0.094 & 0.77 & 0.064 & -0.021 & 0.066 & 0.79 & 0.082 \\
\hline ASCAT & -0.023 & 0.123 & 0.23 & 0.063 & 0.029 & 0.114 & 0.21 & 0.06 \\
\hline SMOS-L2 & -0.019 & 0.109 & 0.45 & 0.058 & 0.001 & 0.071 & 0.71 & 0.078 \\
\hline AMSR-E & -0.103 & 0.126 & 0.36 & 0.108 & -0.037 & 0.084 & 0.64 & 0.101 \\
\hline SCAN & 2002 & Crescent & Lake & & & & & \\
\hline SMOS-L3 & - & - & - & - & 0.042 & 0.074 & 0.27 & 0.059 \\
\hline ECMWF & - & - & - & - & 0.044 & 0.06 & 0.62 & 0.062 \\
\hline SMOS-NN & - & - & - & - & 0.076 & 0.094 & 0.31 & 0.043 \\
\hline ASCAT & - & - & - & - & 0.133 & 0.145 & 0.33 & 0.06 \\
\hline SMOS-L2 & - & - & - & - & 0.018 & 0.066 & 0.15 & 0.046 \\
\hline
\end{tabular}


Table A1 (continued)

\begin{tabular}{|c|c|c|c|c|c|c|c|c|}
\hline \multirow{2}{*}{ Data } & Bias & RMSE & $\mathrm{R} 2$ & std & Bias & RMSE & $\mathrm{R} 2$ & std \\
\hline & \multicolumn{4}{|l|}{ Ascending } & \multicolumn{4}{|c|}{ Descending } \\
\hline AMSR-E & - & - & - & - & - & - & - & - \\
\hline SCAN & 2084 & UAPB & Marianna & & & & & \\
\hline SMOS-L3 & -0.063 & 0.087 & 0.32 & 0.054 & -0.077 & 0.101 & 0.14 & 0.07 \\
\hline ECMWF & -0.001 & 0.07 & 0.25 & 0.056 & -0.033 & 0.067 & 0.23 & 0.065 \\
\hline SMOS-NN & -0.031 & 0.074 & 0.29 & 0.062 & -0.06 & 0.087 & 0.13 & 0.065 \\
\hline ASCAT & -0.025 & 0.075 & 0.3 & 0.055 & -0.078 & 0.111 & 0.25 & 0.091 \\
\hline SMOS-L2 & -0.089 & 0.097 & 0.22 & 0.04 & -0.099 & 0.11 & 0.11 & 0.041 \\
\hline AMSR-E & -0.014 & 0.079 & 0.14 & 0.055 & - & - & - & - \\
\hline AMMA & Benin & & & & & & & \\
\hline SMOS-L3 & 0.121 & 0.136 & 0.76 & 0.114 & 0.092 & 0.106 & 0.71 & 0.097 \\
\hline ECMWF & 0.257 & 0.263 & 0.67 & 0.096 & 0.265 & 0.268 & 0.76 & 0.087 \\
\hline SMOS-NN & 0.058 & 0.069 & 0.79 & 0.082 & 0.086 & 0.099 & 0.72 & 0.095 \\
\hline ASCAT & 0.134 & 0.154 & 0.76 & 0.13 & 0.152 & 0.165 & 0.84 & 0.124 \\
\hline SMOS-L2 & 0.096 & 0.106 & 0.76 & 0.093 & 0.078 & 0.088 & 0.73 & 0.079 \\
\hline AMSR-E & 0.174 & 0.206 & 0.43 & 0.148 & 0.148 & 0.167 & 0.58 & 0.117 \\
\hline AMMA & Niger & & & & & & & \\
\hline SMOS-L3 & 0.02 & 0.055 & 0.67 & 0.072 & 0.008 & 0.031 & 0.64 & 0.047 \\
\hline ECMWF & 0.046 & 0.058 & 0.29 & 0.04 & 0.046 & 0.058 & 0.24 & 0.04 \\
\hline SMOS-NN & 0.033 & 0.058 & 0.63 & 0.067 & 0.02 & 0.046 & 0.63 & 0.06 \\
\hline ASCAT & 0.078 & 0.112 & 0.18 & 0.088 & 0.069 & 0.101 & 0.25 & 0.084 \\
\hline SMOS-L2 & 0.021 & 0.051 & 0.53 & 0.063 & - & - & - & - \\
\hline AMSR-E & 0.004 & 0.039 & 0.36 & 0.048 & 0.002 & 0.031 & 0.55 & 0.045 \\
\hline HOBE & Denmark & & & & & & & \\
\hline SMOS-L3 & -0.017 & 0.066 & 0.52 & 0.085 & -0.09 & 0.096 & 0.72 & 0.059 \\
\hline ECMWF & 0.022 & 0.035 & 0.7 & 0.051 & 0.032 & 0.037 & 0.75 & 0.039 \\
\hline SMOS-NN & -0.029 & 0.044 & 0.61 & 0.053 & -0.102 & 0.105 & 0.5 & 0.028 \\
\hline ASCAT & 0.169 & 0.206 & 0.47 & 0.087 & 0.062 & 0.08 & 0.55 & 0.073 \\
\hline SMOS-L2 & -0.026 & 0.059 & 0.24 & 0.061 & -0.104 & 0.12 & 0.23 & 0.07 \\
\hline AMSR-E & - & - & - & - & - & - & - & - \\
\hline Watershed & Little & Washita & - & US & & & & \\
\hline SMOS-L3 & 0.029 & 0.052 & 0.64 & 0.068 & 0.016 & 0.041 & 0.69 & 0.067 \\
\hline ECMWF & 0.092 & 0.101 & 0.52 & 0.06 & 0.095 & 0.104 & 0.63 & 0.07 \\
\hline SMOS-NN & 0.046 & 0.061 & 0.75 & 0.07 & 0.01 & 0.037 & 0.75 & 0.069 \\
\hline ASCAT & -0.013 & 0.048 & 0.36 & 0.053 & 0.005 & 0.064 & 0.42 & 0.084 \\
\hline SMOS-L2 & 0.014 & 0.041 & 0.62 & 0.062 & -0.002 & 0.035 & 0.64 & 0.059 \\
\hline AMSR-E & 0.037 & 0.08 & 0.34 & 0.088 & 0.04 & 0.069 & 0.46 & 0.077 \\
\hline
\end{tabular}

\section{References}

Al Bitar, A., Leroux, D., Kerr, Y. H., Merlin, O., Richaume, P., Sahoo, A., \& Wood, E. F. (2012) Evaluation of SMOS soil moisture products over continental US using the SCAN SNOTEL Network. IEEE Transactions on Geoscience and Remote Sensing, 50, 1572-1586.

Al Bitar, A., Mialon, A., Kerr, Y., Jacquette, E., Cabot, F., Richaume, P., ... Wigneron, J. -P. (2016). The SMOS Level 3 daily soil moisture maps using multi-orbit retrieval algorithm. Remote Sensing of Environment (submitted for publication).

Albergel, C., de Rosnay, P., Gruhier, C., Munoz-Sabater, J., Hasenauer, S., Isaksen, L., .. Wagner, W. (2012). Evaluation of remotely sensed and modelled soil moisture products using global ground-based in situ observations. Remote Sensing of Environment, $118,215-226$.

Al-Yaari, A., Wigneron, J. P., Ducharne, A., Kerr, Y. H., Wagner, W., De Lannoy, G., ... Mialon, A. (2014b). Global-scale comparison of passive (SMOS) and active (ASCAT) satellite based microwave soil moisture retrievals with soil moisture simulations (MERRALand). Remote Sensing of Environment, 152, 614-626.

Al-Yaari, A., Wigneron, J. P., Ducharne, A., Kerr, Y., de Rosnay, P., de Jeu, R., ... Mialon, A (2014a). Global-scale evaluation of two satellite-based passive microwave soil moisture datasets (SMOS and AMSR-E) with respect to land data assimilation system estimates. Remote Sensing of Environment, 149, 181-195.

Al-Yaari, A., Wigneron, J. -P., Kerr, Y. H., de Jeu, R., Rodriguez-Fernandez, N., van der Schalie, R., ... Ducharne, A. (2016). Testing regression equations to derive long-term global soil moisture datasets from passive microwave observations. Remote Sensing of Environment, 180, 453-464 (in this issue).

dall'Amico, J. T., Schlenz, F., Loew, A., Mauser, W., Kainulainen, J., Balling, J. E., \& Bouzinac, C. (2013). The SMOS validation campaign 2010 in the upper danube catchment: A data set for studies of soil moisture, brightness temperature, and their spatial variability over a heterogeneous land surface. IEEE Transactions on Geoscience and Remote Sensing, 51, 364-377.

Balsamo, G., Beljaars, A., Scipal, K., Viterbo, P., van den Hurk, B., Hirschi, M., \& Betts, A. K. (2009). A revised hydrology for the ECMWF model: Verification from field site to terrestrial water storage and impact in the integrated forecast system. Journal of Hydrometeorology, 10, 623-643.

Bartalis, Z., Naeimi, V., Hasenauer, S., \& Wagner, W. (2008). In I.o.P.a.R. Sensing (Ed.), ASCAT Soil Moisture Report Series. Wien Austria: Vienna University of Technology, ASCAT Soil Moisture Product Handbook.
Bell, J. E., Palecki, M. A., Baker, C. B., Collins, W. G., Lawrimore, J. H., Leeper, R. D., ... Diamond, H. J. (2013). U.S. climate reference network soil moisture and temperature observations. Journal of Hydrometeorology, 14, 977-988.

Bindlish, R., \& Barros, A. P. (2002). Subpixel variability of remotely sensed soil moisture: An inter-comparison study of SAR and ESTAR. IEEE Geoscience and Remote Sensing, 40, 326-337.

Bircher, S., Balling, J. E., Skou, N., \& Kerr, Y. H. (2012a). Validation of SMOS brightness temperatures during the HOBE airborne campaign, Western Denmark. IEEE Transactions on Geoscience and Remote Sensing, 50, 1468-1482.

Bircher, S., Merlin, O., Andreasen, L. A., Andreasen, M., Sonnenborg, T., Jensen, K. H., \& Kerr, Y. H. (2012b). Estimation of the effective SMOS soil moisture sampling depth over the Danish validation/calibration site in the Skjern river catchment. In IEEE (Ed.), IEEE International Geoscience and Remote Sensing Symposium. Munich, Germany.

Bircher, S., Razafindratsima, S., Demontoux, F., Andreasen, M., Vuollet, J., Rautiainen, K., ... Kerr, Y. H. (2014a). Soil moisture and dielectric constant measurements of organic soils in the higher northern latitudes in support of the SMOS mission. Fourth International Symposium on Soil Water Measurement using Capacitance, Impedance and TDT. Montreal Canada.

Bircher, S., Skou, N., Jensen, K. H., Walker, J. P., \& Rasmussen, L. (2012c). A soil moisture and temperature network for SMOS validation in Western Denmark. Hydrology and Earth System Sciences, 16, 1445-1463.

Bircher, S., Skou, N., \& Kerr, Y. H. (2013). Validation of SMOS L1C and L2 products and important parameters of the retrieval algorithm in the skjern river catchment, Western Denmark. IEEE Transactions on Geoscience and Remote Sensing, 51, 2969-2985.

Bircher, S., Wigneron, J. -P., Demontoux, F., Schwank, M., Jonard, F., Razafindratsima, S., ... Kerr, Y. H. (2014b). SMOSHiLat - Microwave L-band emission from organic-rich soils in the northern cold climate zone in the frameworkof the SMOS mission. In IEEE (Ed.), International Geoscience and Remote Sensing Symposium (IGARSS). Quebec Canada: IEEE.

Boussetta, S., Balsamo, G., Beljaars, A., Kral, T., \& Jarlan, L. (2013). Impact of a satellitederived leaf area index monthly climatology in a global numerical weather prediction model. International Journal of Remote Sensing, 34, 3520-3542.

Brodzik, M. J., Billingsley, B., Haran, T., Raup, B., \& Savoie, M. H. (2012). EASE-Grid 2.0: Incremental but significant improvements for earth-gridded data sets. ISPRS International Journal of Geo-Information, 1, 32-45.

Broxton, P. D., Zeng, X., Sulla-Menashe, D., \& Troch, P. (2014). A global land cover climatology using MODIS data. Journal of Applied Meteorology and Climatology, 1593-1605. 
Chung, D., de Jeu, R. A. M., Dorigo, W., Hahn, S., Melzer, T., Parinussa, R. M., ... Wagner, W. (2013). Algorithm theoretical baseline document (ATDB) version 1. Climate Change Initiative Phase 1 Soil Moisture Project.

Crow, W. T., Chen, F., Colliander, A., \& Cosh, M. H. (2015). Application of triple collocation for the ground-based validation of soil moisture active/passive (SMAP) soil moisture data products. In IEEE (Ed.), IGARSS 2015. Milan Italy.

Demarest, P., Good, S., \& Rand, D. (2001). Ascent plan for aqua (EOS-PM1) including phasing with terra (EOS-AM1). Proceedings of 16th International Symposium on Space Flight Dynamics. Pasadena, Ca, USA.

Dobson, M. C., Ulaby, F. T., Hallikainen, M. T., \& Elrayes, M. A. (1985). Microwave dielectric behavior of wet soil 0.2. Dielectric mixing models. IEEE Transactions on Geoscience and Remote Sensing, 23, 35-46.

Dorigo, W. A., Scipal, K., Parinussa, R. M., Liu, Y. Y., Wagner, W., de Jeu, R. A. M., \& Naeimi, V. (2010). Error characterisation of global active and passive microwave soil moisture datasets. Hydrology and Earth System Sciences, 14, 2605-2616.

Dorigo, W. A., Wagner, W., Hohensinn, R., Hahn, S., Paulik, C., Xaver, A., ... Jackson, T. (2011). The international soil moisture network: A data hosting facility for global in situ soil moisture measurements. Hydrology and Earth System Sciences, 15, 1675-1698.

Draper, C., Reichle, R., de Jeu, R., Naeimi, V., Parinussa, R., \& Wagner, W. (2013). Estimating root mean square errors in remotely sensed soil moisture over continental scale domains. Remote Sensing of Environment, 137, 288-298.

Dutra, E., Balsamo, G., Viterbo, P., Miranda, P. M., Beljaars, A., Schär, C., \& Elder, K. (2010). An improved snow scheme for the ECMWF land surface model: Description and offline validation. Journal of Hydrometeorology, 11, 899-916.

Entekhabi, D., Njoku, E. G., O'Neill, P. E., Kellogg, K. H., Crow, W. T., Edelstein, W. N., ... Van Zyl, J. (2010). The soil moisture active passive (smap) mission. Proceedings of the IEEE, 98, 704-716.

Entekhabi, D., Yueh, S., ONeill, P.,. K,. K. K., et al. (2014). SMAP handbook. In J. P. Laboratory (Ed.), JPL Publication JPL 400-1567. Pasadena, CA, USA: NASA CalTech.

Famiglietti, J. S., Devereaux, J. A., Laymon, C. A., Tsegaye, T., Houser, P. R., Jackson, T. J., ... van Oevelen, P. J. (1999). Ground-based investigation of soil moisture variability within remote sensing footprints during the Southern Great Plains 1997 (SGP97) hydrology experiment. Water Resources Research, 35, 1839-1851.

FAO, IIASA, ISRIC, ISSCAS, JRC (2009). Harmonized World Soil Database (Version 1.1). FAO/IIASA. Rome, Italy/Laxenburg, Austria.

Friedl, M. A., Sulla-Menashe, D., Tan, B., Schneider, A., Ramankutty, N., Sibley, A., \& Huang, X. (2010). MODIS collection 5 global land cover: Algorithm refinements and characterization of new datasets. Remote Sensing of Environment, 114, 168-182.

Fujii, H., Koike, T., \& Imaoka, K. (2009). Improvement of the AMSR-E algorithm for soil moisture estimation by introducing a fractional vegetation coverage dataset derived from MODIS data. Journal of the Meteorological Society of Japan, 29, 282-292.

Gevaert, A. I., Parinussa, R. M., Renzullo, L. J., van Dijk, A. I. J. M., \& de Jeu, R. A. M. (2016). Spatio-temporal evaluation of resolution enhancement for passive microwave soil moisture and vegetation optical depth. International Journal of Applied Earth Observation and Geoinformation, 45, 235-244.

Imaoka, K., Kachi, M., Kasahara, M., Ito, N., Nakagawa, K., \& Oki, T. (2010). Instrument performance and calibration of AMSR-E and AMSR2. The International Archives of the Photogrammetry, Remote Sensing and Spatial Information Sciences, 38.

Jackson, T. J., \& Schmugge, T. J. (1989). Passive microwave remote sensing system for soil moisture: some supporting research. IEEE Transactions on Geoscience Electronics, 27, 225-235.

Jackson, T. J., Bindlish, R., Cosh, M. H., Zhao, T. J., Starks, P. J., Bosch, D. D., ... Leroux, D. (2012). Validation of soil moisture and ocean salinity (SMOS) soil moisture over watershed networks in the U.S. IEEE Transactions on Geoscience and Remote Sensing, 50, 1530-1543.

Jackson, T. J., Cosh, M. H., Bindlish, R., Starks, P. J., Bosch, D. D., Seyfried, M., ... Du, J. (2010). Validation of advanced microwave scanning radiometer soil moisture products. IEEE Transactions on Geoscience and Remote Sensing, 48.

Jacquette, E., Al Bitar, A., Mialon, A., Kerr, Y., Quesney, A., Cabot, F., \& Richaume, P. (2010). SMOS CATDS level 3 global products over land. In C. M. U. Neale, \& A. Maltese (Eds.), Remote Sensing for Agriculture, Ecosystems, and Hydrology (pp. Xii).

JAXA (2006). AMSR-E data users handbook. In J.J.A.E. Agency (Ed.), NCX-030021 (4th ed.) (http://www.eorc.jaxa.jp/en/hatoyama/amsr-e/amsr-e_handbook_e.pdf).

de Jeu, R. A. M., Wagner, W., Holmes, T. R. H., Dolman, A. J., Giesen, N. C., \& Friesen, J. (2008). Global soil moisture patterns observed by space borne microwave radiometers and scatterometers. Surveys in Geophysics, 29, 399-420.

Kerr, Y., Waldteufel, P., Richaume, P., Ferrazzoli, P., \& Wigneron, J. -P. (2014). SMOS Level 2 Processor Soil Moisture Algorithm Theoretical Basis Document (ATBD) V4.a. Toulouse: SM-ESL (CBSA), 142.

Kerr, Y. H. (2007). Soil moisture from space: Where are we? Hydrogeology Journal, 15, $117-120$.

Kerr, Y. H., Jacquette, E., Al Bitar, A., Cabot, F., Mialon, A., Richaume, P., ... Berthon, L. (2013). In CBSA (Ed.), CATDS SMOS L3 Soil Moisture Retrieval Processor Algorithm Theoretical Baseline Document (ATBD) CBSA, Technical Note (pp. 73). Toulouse: CESBIO.

Kerr, Y. H., Waldteufel, P., Richaume, P., Wigneron, J. P., Ferrazzoli, P., Mahmoodi, A., .. Delwart, S. (2012). The SMOS soil moisture retrieval algorithm. IEEE Geoscience and Remote Sensing, 50, 1384-1403.

Kerr, Y. H., Waldteufel, P., Wigneron, J. P., Delwart, S., Cabot, F., Boutin, J., ... Mecklenburg, S. (2010). The SMOS mission: New tool for monitoring key elements of the global water cycle. Proceedings of the IEEE, 98, 666-687.

Kerr, Y. H., Waldteufel, P., Wigneron, J. P., Martinuzzi, J. M., Font, J., \& Berger, M. (2001) Soil moisture retrieval from space: The soil moisture and ocean salinity (SMOS) mission. IEEE Transactions on Geoscience and Remote Sensing, 39, 1729-1735.

Kim, S., Liu, Y. Y., Johnson, F. M., Parinussa, R. M., \& Sharma, A. (2015). A global comparison of alternate AMSR2 soil moisture products: Why do they differ. Remote Sensing of Environment, 161, 43-62.
Koike, T., Nakamura, Y., Kaihotsu, I., Davva, G., Matsuura, N., Tamagawa, K., \& Fujii, H. (2004). Development of an advanced microwave scanning radiometer (AMSR-E) algorithm of soil moisture and vegetation water content. Annual Journal of Hydraulic Engineering, JSCE, 48.

Lafore, J. P., Flamant, C., Giraud, V., Guichard, F., Knippertz, P., Mahfouf, J. F., ... Williams, E. R. (2010). Introduction to the AMMA special issue on 'Advances in understanding atmospheric processes over West Africa through the AMMA field campaign'. Quarterly Journal of the Royal Meteorological Society, 136, 2-7.

Larson, K. M., Small, E. E., Gutmann, E. D., Bilich, A. L., Braun, J. J., \& Zavorotny, V. U. (2008) Geophysical Research Letters, 35.

Le Vine, D. M., Dinnat, E. P., Lagerloef, G. S. E., de Matthaeis, P., Abraham, S., Utku, C., \& Kao, H. (2014). Aquarius: Status and recent results. Radio Science, 49, 709-720.

Leavesley, et al. (2010). A Modelling Framework for Improved Agricultural Water-Supply Forecasting.

Leroux, D. J., Kerr, Y. H., Al Bitar, A., Bindlish, R., Jackson, T. J., Berthelot, B., \& Portet, G. (2014). Comparison between SMOS, VUA, ASCAT, and ECMWF soil moisture products over four watersheds in US. IEEE Transactions on Geoscience and Remote Sensing, 52 1562-1571.

Leroux, D. J., Kerr, Y. H., Richaume, P., \& Fieuzal, R. (2013). Spatial distribution and possible sources of SMOS errors at the global scale. Remote Sensing of Environment, 133 240-250.

Lopez-Baeza, E., Albitar, A., Antolin, M. C., Balling, J., Belda, F., Bouzinac, C., ... Zribi, M. (2010). Towards validation of SMOS land products using the synergy between models, airborne and ground-based data over the Valencia anchor station. Definition of matching-up points to SMOS observations. In IEEE (Ed.), IGARSS '10. Honolulu Hawaii USA: IEEE.

Louvet, S., Pellarin, T., al Bitar, A., Cappelaere, B., Galle, S., Grippa, M., ... de Rosnay, P. (2015). SMOS soil moisture product evaluation over West-Africa from local to regional scale. Remote Sensing of Environment, 156, 383-394.

Mahmoodi, A., Richaume, P., Kerr, Y., Mialon, A., Bircher, S., \& Leroux, D. (2015). Evaluation of MODIS IGBP land cover data on the SMOS level 2 soil moisture retrievals. In ESA (Ed.), ESA SMOS Workshop. Villanfranca de la Canada, Madrid Spain: ESA.

Martin-neira, M., Corbella, I., Torres, F., Durán, I., Duffo, N., Kainulainen, J., ... Suess, M. (2016). Smos instrument performance and calibration after 6 years in orbit. Remote Sensing of Environment, 180, 19-39 (in this issue).

Masson, V., Champeau, J. -L., Chauvin, F., Meriguet, C., \& Lacaze, R. (2003). A global data base of land surface parameters at $1 \mathrm{~km}$ resolution in meteorological and climate models. Journal of Climate, 16, 1261-1282.

Matthews, E. (1983). Global vegetation and land use: New high-resolution data bases for climate studies. Journal of Climate and Applied Meteorology, 22, 474-487.

Mecklenburg, S., Drusch, M., Kerr, Y. H., Font, J., Reul, N., Kaleschke, L., ... Kornberg, M. (2016). ESA's soil moisture and ocean salinity mission: from science to operational applications. Remote Sensing of Environment, 180, 3-18 (in this issue).

Mialon, A., Richaume, P., Leroux, D., Bircher, S., Al Bitar, A., Pellarin, T., ... Kerr, Y. H. (2015). Comparison of Dobson and Mironov dielectric models in the SMOS soil moisture retrieval algorithm. Geoscience and Remote Sensing, IEEE Transactions on, 53, 3084-3094.

Mironov, V. L., Kosolapova, L. G., \& Fomin, S. V. (2009). Physically and mineralogically based spectroscopic dielectric model for moist soils. Geoscience and Remote Sensing, IEEE Transactions on, 47, 2059-2070.

Mo, T., Choudhury, B. J., Schmugge, T. J., Wang, J. R., \& Jackson, T. J. (1982). A model for microwave emission from vegetation-covered fields. Journal of Geophysical Research Oceans and Atmospheres, 87, 1229-1237.

Montzka, C., Bogena, H. R., Weihermueller, L., Jonard, F., Bouzinac, C., Kainulainen, J., .. Vereecken, H. (2013). Brightness temperature and soil moisture validation at different scales during the SMOS validation campaign in the Rur and Erft Catchments, Germany. IEEE Transactions on Geoscience and Remote Sensing, 51, 1728-1743.

Naeimi, V., Scipal, K., Bartalis, Z., Hasenauer, S., \& Wagner, W. (2009). An improved soil moisture retrieval algorithm for ERS and METOP scatterometer observations. IEEE Transactions on Geoscience Electronics, 47, 1999-2013.

Nicolai-Shaw, N., Hirschi, M., Mittelbach, H., \& Seneviratne, S. I. (2015). Spatial representativeness of soil moisture using in situ, remote sensing, and land reanalysis data. Journal of Geophysical Research-Atmospheres, 120.

Njoku, E. G., Jackson, T. J., Lakshmi, V., Chan, T. K., \& Nghiem, S. V. (2003). Soil moisture retrieval from AMSR-E. Geoscience and remote sensing. IEEE Transactions on Geoscience Electronics, 41, 215-229.

Ochsner, T. E., Cosh, M. H., Cuenca, R. H., Dorigo, W. A., Draper, C. S., Hagimoto, Y., ... Zreda, M. (2013). State of the art in large-scale soil moisture monitoring. Soil Science Society of America Journal, 77, 1888-1919.

Oliva, R., Daganzo, E., Richaume, P., Kerr, Y., Cabot, F., Soldo, Y., ... Lopes, G. (2016). Status of Radio Frequency Interference (RFI) in the 1400-1427 MHz passive band based on six years of SMOS mission. Remote Sensing of Environment, 180, 64-75 (in this issue).

Owe, M., de Jeu, R., \& Holmes, T. (2008). Multisensor historical climatology of satellitederived global land surface moisture. Journal of Geophysical Research - Earth Surface, 113.

Owe, M., de Jeu, R., \& Walker, J. (2001). A methodology for surface soil moisture and veg etation optical depth retrieval using the microwave polarization difference index IEEE Transactions on Geoscience Electronics, 39, 1643-1654.

Parrens, M., Wigneron, J. P., Richaume, P., Kerr, Y., Wang, S., Alyaari, A., et al. (2014). Global maps of roughness parameters from L-band SMOS observations. In IEEE (Ed.) 2014 IEEE International Geoscience and Remote Sensing Symposium. Quebec Canada: IEEE. http://dx.doi.org/10.1109/igarss.2014.6947536.

Reichle, R. H. (2012). In GMAO (Ed.), The MERRA-Land Data Product (pp. 38). GMAO.

Reichle, R. H., Koster, R. D., De Lannoy, G. J. M., Forman, B. A., Liu, Q., Mahanama, S. P. P., \& Touré, A. (2011). Assessment and enhancement of MERRA land surface hydrology estimates. Journal of Climate, 24, 6322-6338. 
Robinson, D. A., Campbell, C. S., Hopmans, J. W., Hornbuckle, B. K., Jones, S. B., Knight, R., Wendroth, O. (2008). Soil moisture measurement for ecological and hydrological watershed-scale observatories: a review. Vadose Zone Journal, 7, 358-389.

Rodriguez-Fernandez, N. J., Aires, F., Richaume, P., Kerr, Y. H., Prigent, C., Kolassa, J., .. Drusch, M. (2015). Soil moisture retrieval using neural networks: application to SMOS. IEEE Transactions on Geoscience and Remote Sensing, 53(11), 5991-6007.

Rondinelli, W. J., Hornbuckle, B. K., Patton, J. C., Cosh, M. H., Walker, V. A., Carr, B. D., \& Logsdon, S. D. (2015). Different rates of soil drying after rainfall are observed by the SMOS satellite and the South Fork in situ soil moisture network. Journal of Hydrometeorology, 16, 889-903.

de Rosnay, P., et al. (2012). A simplified extended Kalman filter for the global operationa soil moisture analysis at ECMWF. Quarterly Journal of the Royal Meteorological Society, 139, 1199-1213.

Rotzer, K., Montzka, C., Bogena, H., Wagner, W., Kerr, Y. H., Kidd, R., \& Vereecken, H. (2014). Catchment scale validation of SMOS and ASCAT soil moisture products using hydrological modeling and temporal stability analysis. Journal of Hydrology, 519, 934-946.

Rüdiger, C., Calvet, J. -C., Gruhier, C., Holmes, T. R. H., de Jeu, R. A. M., \& Wagner, W. (2009) An intercomparison of ERS-Scat and AMSR-E soil moisture observations with mode simulations over France. Journal of Hydrometeorology, 10, 431-447.

Rüdiger, C., Western, A. W., Walker, J. P., Smith, A. B., Kalma, J. D., \& Willgoose, G. R. (2010). Towards a general equation for frequency domain reflectometers. Journal of Hydrology, 383, 319-329.

Sanchez, N., Martinez-Fernandez, J., Scaini, A., \& Perez-Gutierrez, C. (2012). Validation of the SMOS L2 soil moisture data in the REMEDHUS Network (Spain). IEEE Transactions on Geoscience and Remote Sensing, 50, 1602-1611.

Schaefer, G. L., Cosh, M. H., \& Jackson, T. J. (2007). The USDA natural resources conservation service soil climate analysis network (SCAN). Journal of Atmospheric and Oceanic Technology, 24, 2073-2077.

Scipal, K., Holmes, T., de Jeu, R., Naeimi, V., \& Wagner, W. (2008). A possible solution for the problem of estimating the error structure of global soil moisture data sets. Geophysical Research Letters, 35.
Smith, A. B , Walker J. P. Western, A. W Young R. I, Ellett, K. M., Pipunic, R. C .... Chiew, F. H. S. (2012). The Murrumbidgee soil moisture monitoring network data set. Water Resources Research, 48

Stoffelen, A. (1998). Toward the true near-surface wind speed: Error modeling and calibration using triple collocation. Journal of Geophysical Research, Oceans, 103, $7755-7766$

Tagesson, T., Fensholt, R., Guiro, I., et al. (2014). Ecosystem properties of semi-arid savanna grassland in West Africa and its relationship to environmental variability. Global Change Biology.

Tarantola, A. (2004). Inverse Problem Theory and Methods for Model Parameter Estimation. Philadelphia, PA, USA.

Taylor, K. E. (2001). Summarizing multiple aspects of model performance in a single diagram. Journal of Geophysical Research-Atmospheres, 106, 7183-7192.

Ulaby, F. T., Moore, R. K., \& Fung, A. K. (1981). Microwave Remote Sensing - Active and Passive. Norwood, USA: Artech House.

Vaz, C. M. P., Jones, S., Meding, M., \& Tuller, M. (2013). Evaluation of standard calibration functions for eight electromagnetic soil moisture sensors. Vadose Zone Journal, 12.

Vittucci, C., Ferrazzoli, P., Kerr, Y., Richaume, P., Rahmoune, R., Guerriero, L., \& Vaglio Laurin, G. (2016). Smos retrieval over forests: Exploitation of optical depth and tests of soil moisture estimates. Remote Sensing of Environment, 180, 115-127 (in this issue).

Wagner, W., Hahn, S., Kidd, R., Melzer, T., Bartalis, Z., Hasenauer, S., ... Steinnocher, K. (2013). The ASCAT soil moisture product: A review of its specifications, validation results, and emerging applications. Meteorologische Zeitschrift, 22, 5-33.

Wagner, W., Lemoine, G., \& Rott, H. (1999). A method for estimating soil moisture from ERS scatterometer and soil data. Remote Sensing of Environment, 70, 191-207.

Wigneron, J. -P., Kerr, Y., Waldteufel, P., Saleh, K., Escorihuela, M. -J., Richaume, P., ... Mätzler, C. (2007). L-band microwave emission of the biosphere (L-MEB) model: Results from calibration against experimental data sets over crop fields. Remote Sensing of Environment, 107, 639-655. 